\title{
Assessment of Land Erosion and Sediment Accumulation Caused by Runoff after a Flash-Flooding Storm Using Topographic Profiles and Spectral Indices
}

\author{
A. Bannari', G. Kadhem1', A. El-Battay¹, N. A. Hameid', M. Rouai² \\ ${ }^{1}$ Department of Geoinformatics, College of Graduate Studies, Arabian Gulf University, Manama, Kingdom of Bahrain \\ ${ }^{2}$ Department of Earth Sciences, Faculty of Sciences, University Moulay Ismail, Meknes, Morocco \\ Email: abannari@agu.edu.bh, Mohamed.rouai@gmail.com
}

How to cite this paper: Bannari, A., Kadhem, G., El-Battay, A., Hameid, N.A. and Rouai, M. (2016) Assessment of Land Erosion and Sediment Accumulation Caused by Runoff after a Flash-Flooding Storm Using Topographic Profiles and Spectral Indices. Advances in Remote Sensing, 5, 315-354. http://dx.doi.org/10.4236/ars.2016.54024

Received: October 4, 2016

Accepted: December 12, 2016

Published: December 15, 2016

Copyright $\odot 2016$ by authors and Scientific Research Publishing Inc. This work is licensed under the Creative Commons Attribution International License (CC BY 4.0).

http://creativecommons.org/licenses/by/4.0/ (c) (i) Open Access

\section{Abstract}

This research deals with the characterization of areas associated with flash floods and erosion caused by severe rainfall storm and sediment transport and accumulation using topographic attributes and profiles, spectral indices (SI), and principal component analysis (PCA). To achieve our objectives, topographic attributes and profiles were retrieved from ASTER-V2 DEM. PCA and nine SI were derived from two Landsat-OLI images acquired before and after the flood-storm. The images data were atmospherically corrected, sensor radiometric drift calibrated, and geometric and topographic distortions rectified. For validation purposes, the acquired photos during the flood-storm, lithological and geological maps were used. The analysis of approximately 100 colour composite combinations in the RGB system permitted the selection of two combinations due to their potential for characterizing soil erosion classes and sediment accumulation. The first considers the "Intensity, NDWI and NMDI", while the second associates form index (FI), brightness index (BI) and NDWI. These two combinations provide very good separating power between different levels of soil erosion and degradation. Moreover, the derived erosion risk and sediment accumulation map based on the selected spectral indices segmentation and topographic attributes and profiles illustrated the tendency of water accumulation in the landscape, and highlighted areas prone to both fast moving and pooling water. In addition, it demonstrated that the rainfall, the topographic morphology and the lithology are the major contributing factors for flash flooding, catastrophic inundation, and erosion risk in the study area. The runoff-water power delivers vulnerable topsoil and contributes strongly to the erosion process, and then transports soil material and sediment to the plain areas through waterpower and gravity. The originality of this 
research resides in its simplicity and rapidity to provide a solid basis strategy for regional policies to address the real causes of problems and risks in developing countries. Certainly, it can help in the improvement of the management of water regulation structures to develop a methodology to maximize the water storage capacity and to reduce the risks caused by floods in the Moroccan Atlas Mountain (Guelmim region).

\section{Keywords}

Soil Erosion, Sediments Transport and Accumulation, Flood-Storm, Runoff, Climate Change, Remote Sensing, GIS, Topographic Profiles, Landsat-8, ASTER-DEM

\section{Introduction}

During the last four decades, the impact of climate change becomes an undeniable reality, with a broad consensus of the international scientific community on the significance of its impact on the environment, economic and social factors, especially in African countries [1]. Morocco is a North-African country with a dominant (mostly) semiarid to arid climate and presents typical characteristics of Mediterranean landscapes vulnerable to land degradation processes, landslides and desertification risks [2] [3]. Currently, Morocco is experiencing the longest dry episode of its contemporary history characterized by a reduction of precipitation and a rise in temperatures. These climate conditions limit the growth of the vegetation cover (sparse and scattered), especially in High Atlas Mountain areas. This situation in conjunction with the human activities leads to a degradation and erosion of soil by wind and water. In addition, the rain fall rarely occurs, but with high intensity during a short period of time, which causes flooding problems and accelerates the erosion phenomenon and land degradation. According to Erskine and Saynor [4], catastrophic floods are defined as events with a flood peak discharge at a rate of at least 10 times greater than the mean annual flood. Heavy rains often induce floods in Morocco, including flash floods, rivers floods and mud floods during the rainy season. Indeed, in November 2014, violent storms have caused flooding and impressive river floods in a large part of southern Morocco, especially in the city of Guelmim and regions, which are localized at the foot of the Atlas Mountains, with peaks rising to over $4000 \mathrm{~m}$. According to SIGMA [5], this natural catastrophe caused the death of more than 46 persons and a significant damage to the infrastructure; villages were inundated (Figure 1) causing thousands of houses to collapse, many oasis and agricultural fields were destructed (Figure 2), power and telephone networks and several roads and bridges were damaged (Figure 3 ). Total losses were estimated about 0.6 billion US\$ [5] [6]. Consequently, the region of Guelmim was declared a "disaster area" by the Moroccan government. This area was not devastated for the first time; it has been flooded several times over the past 50 years, namely in 1968, 1985, 1989, 2002, 2010 and 2014 [6]. Unfortunately, in addition to the climate 
change impact, this situation happened because of the lack of emergency measures, a failure of development policy, carelessness of citizens, as well as the Moroccan decisionmakers have not learned from the past lessons. However, it is very simple to understand and know that the water (River) always takes its course! This is illustrated in Figure 4, showing two Landsat-8 satellite images acquired two weeks before and eight days after the floods. It can be observed that the rains turned the river into a powerful torrent, causing floods of houses and cultivated fields in the middle of the River.

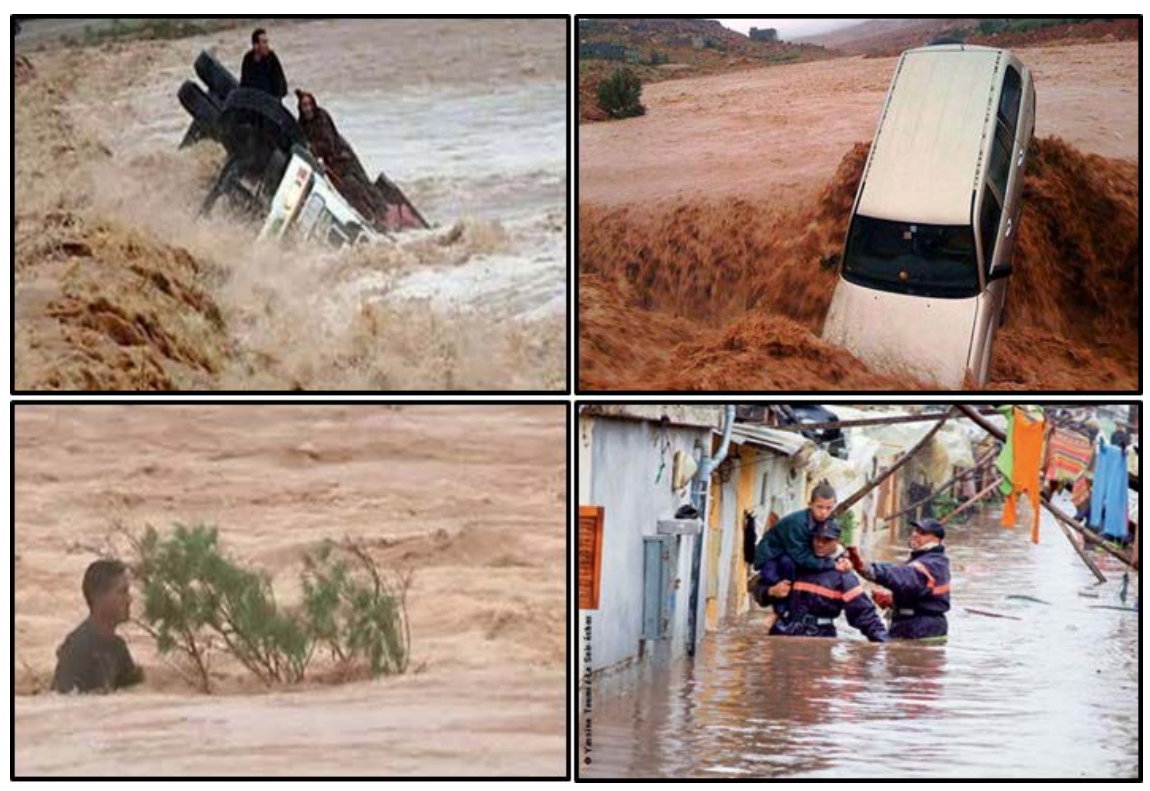

Figure 1. Impressive flood and inundated village in the Guelmim region on 24 November 2014 (Photos from the web).

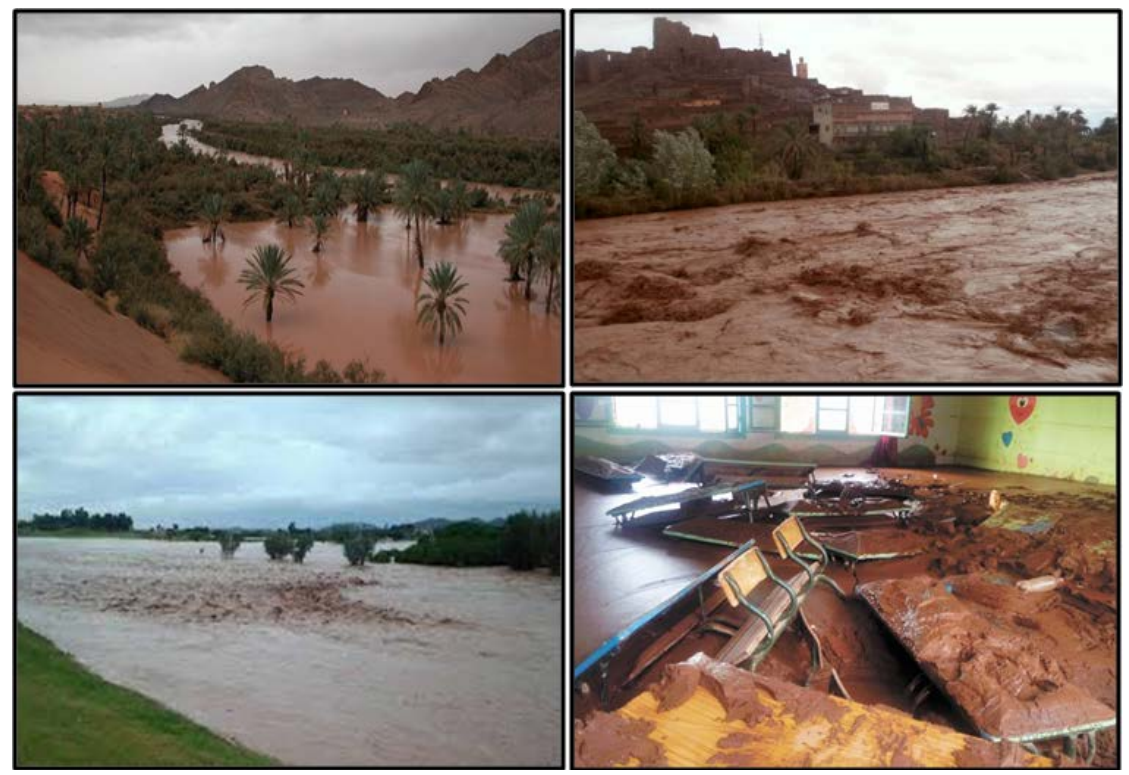

Figure 2. Oasis, agricultural fields and a classroom inundation in the Guelmim city region on 24 November 2014 (Photos from the web). 


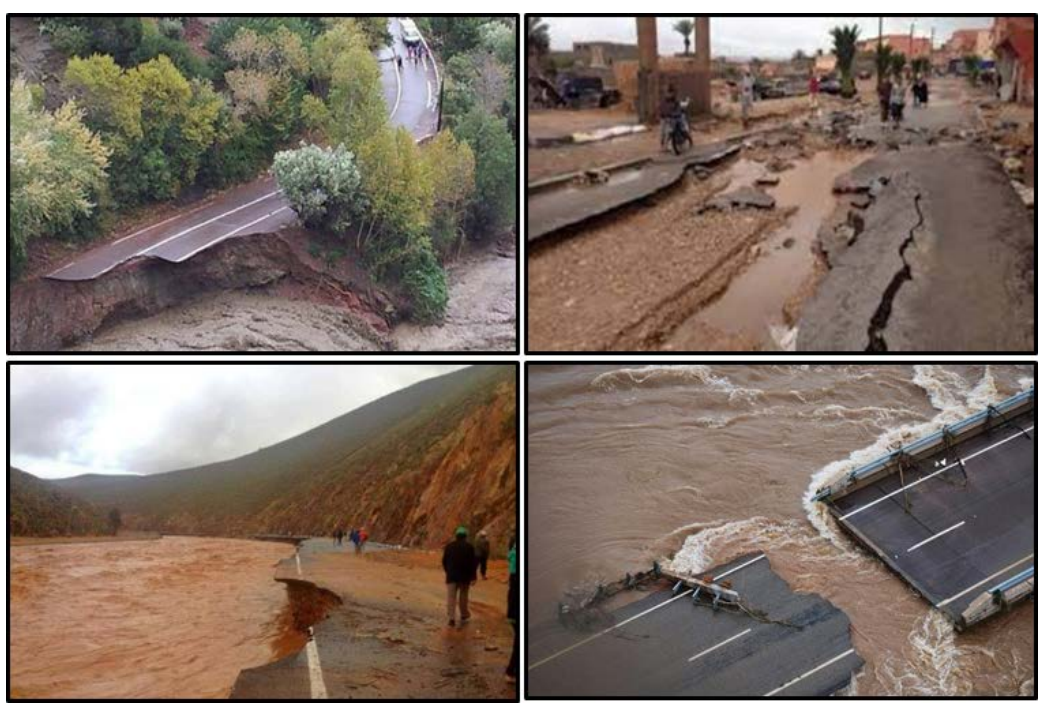

Figure 3. Destruction of road and bridge infrastructure in the Guelmim city region on 24 November 2014 (Photos from the web).

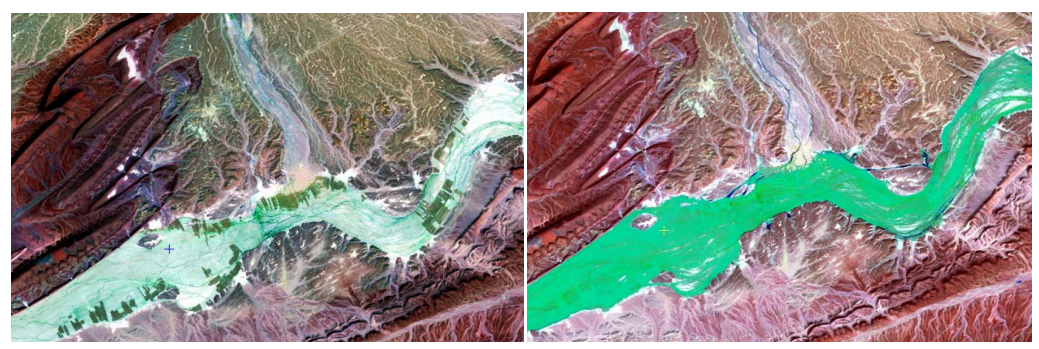

Figure 4. Flooding of houses and cultivated fields in the middle of the River bed two weeks before the floods (left) and eight days after (right).

In order to improve the management of the water regulation structures, there is a need to develop methodology to maximize the water storage capacity and to reduce the risks caused by floods. Previous research activities have developed methodologies based on analyzing correlations between agents of climate, physiography, lithology, vegetation and land use [7]. Unfortunately, few of these parameters can be measured directly, but earlier studies have shown that remote sensing gains increasing importance in providing useful substitute information. However, the extraction of topographic, hydrologic and environmental information from the satellite data remains weakly developed, because of the extreme complexity of the relationship between the spectral response and the environmental parameters [7]. During the last two decades, remote sensing technology associated with geographic information system (GIS) and auxiliary data (especially a digital elevation model: DEM) has become the fundamental solution for flood monitoring [8] and its impact assessment.

In the literature, Huete [9] demonstrated that in arid and semiarid land, the measured remote sensing signals at the sensor level are largely influenced by the soil background. Although certain previous research activities developed methodologies for the removal of the soil contribution to the remotely sensed signal to predict correctly vege- 
tation cover using vegetation indices [10], others developed approaches to enhance information from the soil signal, considering soil colour, brightness, texture, mineralogy, etc. [11] [12]. Indeed, spectral response variation measured at the satellite sensor is an excellent indicator of environmental change [13]. If soil and vegetation in arid land are considered, slight changes in colour and mineralogy in the first and variations in the structure and spatial distribution in the second can constitute indicators of change and degradation in natural environments [14]. The original idea for this approach came from prior research carried out by Baumgardner et al. [15]. Furthermore, Escadafal et al. [11], Hill et al. [16] and Haboudane et al. [13] confirmed that the spectral properties can be related to soil conditions. Consequently, they will be able to lead to understand and infer different soil-degradation forms and to show the potential use of remote sensing for land-degradation characterization. Within this context, numerous studies have shown the interest of spectral indices based on the soil reflectance, such as the form index (FI), the coloration index (CI) and the brightness index (BI) for characterizing soil surface state, particularly in arid and semi-arid areas. In addition to these three indices, soils can also be characterized by intensity $(\mathrm{I})$, hue $(\mathrm{H})$ and saturation $(\mathrm{S})$ that correspond to colour brightness, colour spectral dominance as well as colour purity [17] [18]. Other studies have shown the contribution of principal components analysis (PCA) for the derivation of new information related to degraded and eroded areas according to the vegetation-cover density [3] [19] [20] [21]. In addition, the normalized difference water index (NDWI; [22]) and the normalized multi-band drought index (NMDI; [23]) were developed for both soil and vegetation water content mapping using the near infrared (NIR) and short-wave infrared (SWIR) channels. These indices have a great potential for soil moisture content mapping after flash flood periods [24] [25] [26] and for surface soil moisture variations monitoring in time during dry seasons [27]. Moreover, they could be informative on areas of water and mud convergence and accumulation as well as areas of erosion and runoff. Considering land use, soil erosion increases when the soil has little vegetation cover density. Because the vegetation (green or senescent) protects the soil from the impact of raindrops and splashing, it tends to slow the runoff speed to minimize the effect of erosion and ensure better infiltration and enrichment of soil with the organic matter [28] [29]. To deal with the saturation, the linearity weaknesses, and the soil artifacts effect correction, the transformed difference vegetation index (TDVI) was developed to describe the dynamic range of the vegetation-soil systems, which is linearly independent to external disturbing artifacts [28]. For soil erosion and degradation analysis in arid environment, this index showed a great potential to discriminate accurately the vegetation cover from the other land-use classes [3]. The objective of this research is the assessment of land erosion and sediment accumulation caused by runoff after a flash-flooding storm using topographic attributes and profiles, remote sensing spectral indices and PCA. The originality resides in its simplicity and rapidity of the proposed methodology to provide a solid basis strategy for regional policies to address the real causes of problems and risks in developing countries. 


\section{Material and Methods}

The used methodology is summarized in Figure 5. It involves five fundamental steps: 1) data preprocessing, 2) topographic profile retrieval, 3) soil, vegetation and moisture spectral indices processing, 5) PCA and "I-H-S" calculations, and 4) information integration and segmentation of the landscape into different eroded and degraded units and sediment accumulation.

\subsection{Study Site}

Guelmim is a city in south of Morocco, often called Gateway to the Desert; it is the capital of the Souss-Massa-Drâa region $\left(28^{\circ} 59^{\prime} 02^{\prime \prime N}, 10^{\circ} 03^{\prime} 37^{\prime \prime} \mathrm{W}\right)$. It is located at the foot of the western Anti-Atlas Mountains with peaks rising to over $2100 \mathrm{~m}$ above sea level, and it follows the course of underground shallow aquifers and dry rivers (Figure 6). Settled agriculture developed around underground water sources and dry rivers beds that flood during the rainy season. It is characterized by a semi-arid and arid subtropical climate. The temperature range varies from $12^{\circ} \mathrm{C}$ in January to $49^{\circ} \mathrm{C}$ in July. Annual rainfall averages between 70 and 120 millimeters/year [30]. The Assaka River drains a large watershed on the southwest border of the Anti-Atlas and its Saharan edges in the Guelmim area [31]. Its water shed develops on the southern slopes of the Anti-Atlas [32]. In the lower part of its course, the river valley shows the stepping and the nesting of several alluvial terraces intersecting the Appalachian relief of the Anti-Atlas Mountains and depressions, which offer a landscape of hills and small mountains depending on the resistance of rocks to erosion. The Assaka River, the confluence of the three wadis, Seyyad, Noun and Oum Al-Achar, crosses the last folded chains of the AntiAtlas before flowing into the Atlantic Ocean. In this part of its course, it has aggraded

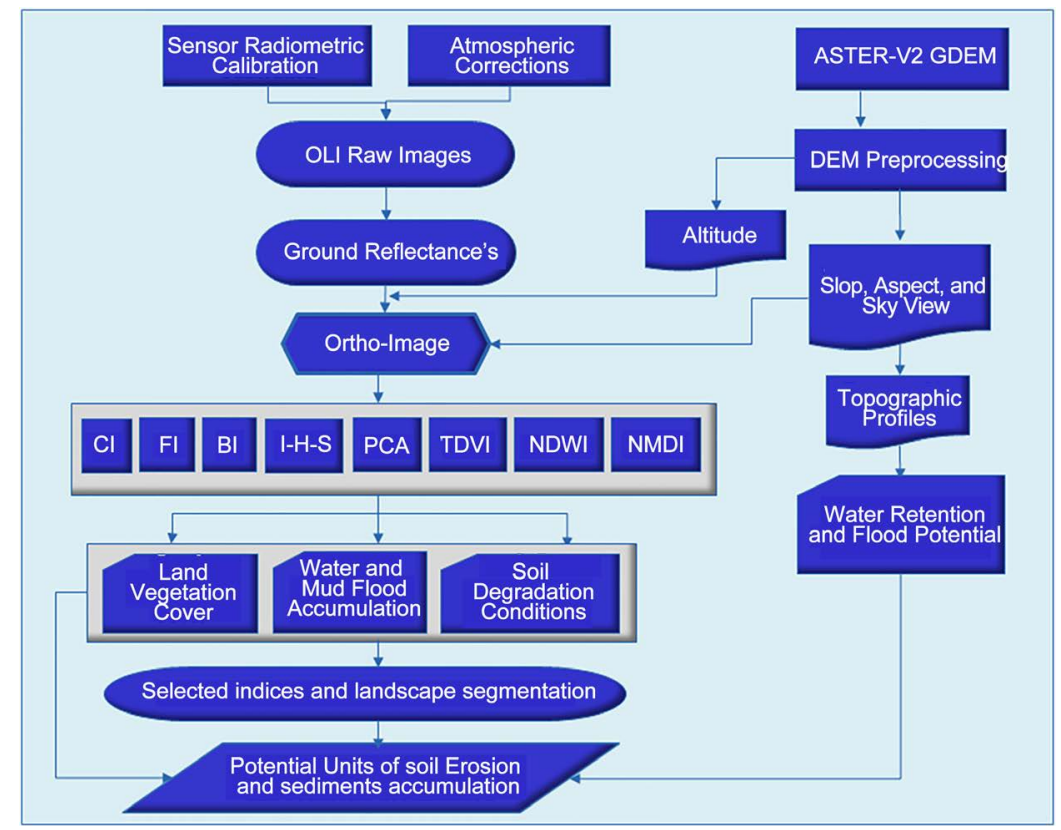

Figure 5. Methodology flowchart. 
a large system of alluvial terraces. The geological for mations that feed alluvium are granite, schist, quartzite, sand stone, limestone, dolomite, marl, conglomerate, andesite and rhyolite (Figure 7). They correspond to the top of the Precambrian (Ifni boutonniere) and lower Paleozoic rock, which forms part of the Anti-Atlas sedimentary cover [32]. From a geological point of view, the study region constitutes a complex synclinal, framed and surrounded in the N, W and S by three Precambrian anticlinal inlets (boutonnieres): Kerdous-Tazeroualt, Ifni and Guir [33]. The two mean structural units in the region are the carbonate plateaus and the folded Bani hills. The most important Infra-Cambrian and Cambrian carbonate plateaus are located in the north, consisting of a continuous area bordering from $\mathrm{W}$ to $\mathrm{E}$ the Ifni Inlet, Akhsass plateau and the southern

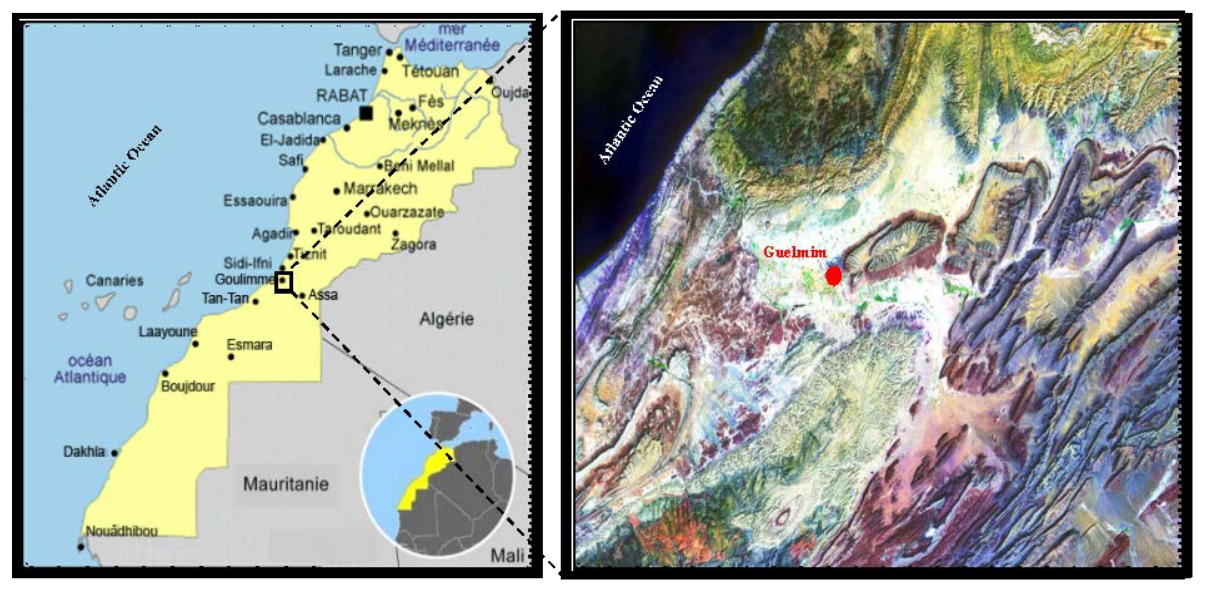

Figure 6. Map of the study site localization (Guelmim city region, Morocco).

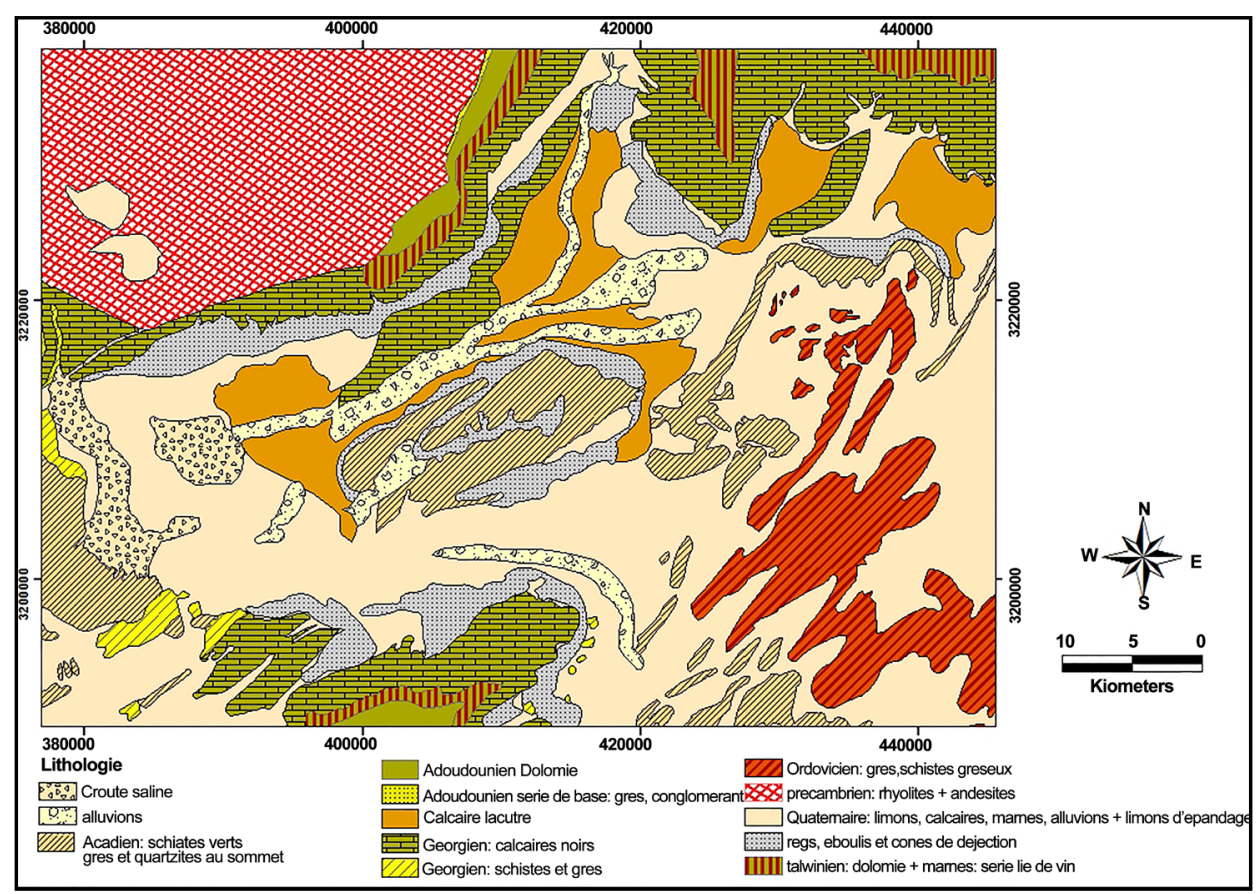

Figure 7. Lithologic map of the study site. 
flank of the Kerdous inlet. The second one, located south, is formed by the external part of Jabal Guir-Taissa. These plateaus are surrounded by schist and sandstone formations of the Georgian age. At their foot begin large and elongated plains, named "feijas", consisting of Acadian schist covered by Quaternary deposits (mainly lacustrine carbonate and silts). At the centre of the Guelmim basin, Jabal Tayert is found which is formed by green Upper Acadian schist and covered at the top by hard sandstone and quartzite bars (Figure 7). The Bani Jabal is a folded structure consisting of several aligned and NE-SW oriented synclinals alternating with narrow anticlinals formed by Acadian or Ordovician sand stones and quartzites.

As we discussed above, the Guelmim water shed covers a total area of approximately $7000 \mathrm{~km}^{2}$, forming a network of wadis (rivers) along with several spreading flood water areas (Figure 8). The hydrographic network is made up of three sub-water sheds of the following main wadis: wadi Seyyad, wadi Noun and wadi OumAl-Achar [32] [34]. Wadi Seyyad originates at an altitude of $1200 \mathrm{~m}$ on the southern slopes of the Anti-Atlas Mountain. It flows in an E-W direction, composed of impermeable rocks and mainly receives numerous tributaries of its right bank; its watershed covers about an area of $2860 \mathrm{~km}^{2}$. Wadi Nound rains the southern area, where the bit marked with river beds which promote natural flooding. With a length of $143 \mathrm{~km}$, its watershed comprises an area of about $2240 \mathrm{~km}^{2}$. The wadi Assaka begins in the Akhsass massive at an altitude of $1150 \mathrm{~m}$. It flows through the corridor between the Jebel Adrar and Guelmim west, discharging into the Atlantic Ocean. Finally, Wadi Oum Al-Achar, with a watershed of $1170 \mathrm{~km}^{2}$, crosses a wide plain of $7 \mathrm{~km}$ and is located between the Tayert hill and Ifni boutonnière. It drains the southern slopes of the Akhsass region, and its main tributaries are located in the plain. All three wadis lie on schistous impermeable large valleys or "feijas", covered by low permeable Quaternary carbonates and fluvio-lacustrine silts. The confluence of the three wadis, downstream from Guelmim city, forms Wadi Assa$\mathrm{ka}$, which begins in the Akhsass massif at an altitude of $1150 \mathrm{~m}$. It goes through the corridor between the Jabal Adrar and Guelmim west, eventually discharging into the Atlantic Ocean after crossing narrow gorges. This hydrographic system is often inactive, especially during the summer, when the flow is very low; however, it becomes active during the winter period (December to March). This configuration is the cause of many talweg sand wadis draining the area. Thus, all the runoffs are directed automatically to the city of Guelmim, which is subject to a hydrological regime unregulated surface.

\subsection{ASTER-V2 GDEM}

The ASTER (Advanced Space borne Thermal Emission and Reflection Radiometer) GDEM (Global Digital Elevation Model) is a joint product developed and made available to the public by the Ministry of Economy, Trade, and Industry (METI) of Japan and the United States National Aeronautics and Space Administration (NASA). It is generated from data collected from the optical instrument ASTER onboard the TERRA spacecraft [35]. This instrument was built in December 1999 with an along-track stereoscopic capability using its nadir-viewing and backward-viewing telescopes to ac- 
quire stereo image data with a base-to-height ratio of 0.6 [36]. Since 2001, these stereo pairs have been used to produce single-scene $(60 \mathrm{~km} \times 60 \mathrm{~km})$ DEM based on a stereo-correlation matching technique using WGS84 geodetic reference data [35]. According to Chrysoulakis et al. [37], the planimetric and altimetric accuracies of the produced ASTER DEM over Greek islands are $\pm 15.00 \mathrm{~m}$ and $\pm 12.41 \mathrm{~m}$, respectively. They considered these accuracies satisfactory for watershed management, hydrological applications, and the ortho-rectification of satellite imagery acquired over the same area with the same spatial resolution, which is the case in this study $(30 \mathrm{~m} \times 30 \mathrm{~m})$. Testing the ASTER GDEM over Vancouver (West Canadian territory), Toutin [38] demonstrated that the derived DEM is almost linearly correlated with the terrain slopes. Based on a set of geodetic ground control points over Western Australia, Hirt et al. [39] have been shown that the vertical accuracy of ASTER GDEM is approximately $\pm 15 \mathrm{~m}$. They also reported that this accuracy varies as a function of the terrain type and shape, and it is relatively low in areas with low topographic variability. In 2011, U.S. and Japanese partners [36] [40] made the validation and the accuracy assessment of the ASTER-V2 GDEM products (version-2) jointly. The results of this study showed that the absolute geometrical calibration accuracies expressed as a linear error at the $95 \%$ confidence lev$\mathrm{el}$, are $\pm 8.68 \mathrm{~m}$ and $\pm 17.01 \mathrm{~m}$, respectively, for planimetry and altimetry [41]. In this study, the ASTER DEM over the Guelmim region (Figure 8) was downloaded from the USGS data explorer gate [42] and was retro-projected in UTM. Then, by referring to a topographic contours map at the scale of $1 / 50,000$, the derived global height surfaces accuracy was calculated: $\pm 9.17 \mathrm{~m}$ [43]. This local accuracy is better than the global one $( \pm 17.01 \mathrm{~m})$ presumed by Meyer [41]. The derived DEM was used for images data ortho-rectification, refinement of atmospheric corrections, topographic attributes derivation, and $3 \mathrm{D}$ visualization and analysis.

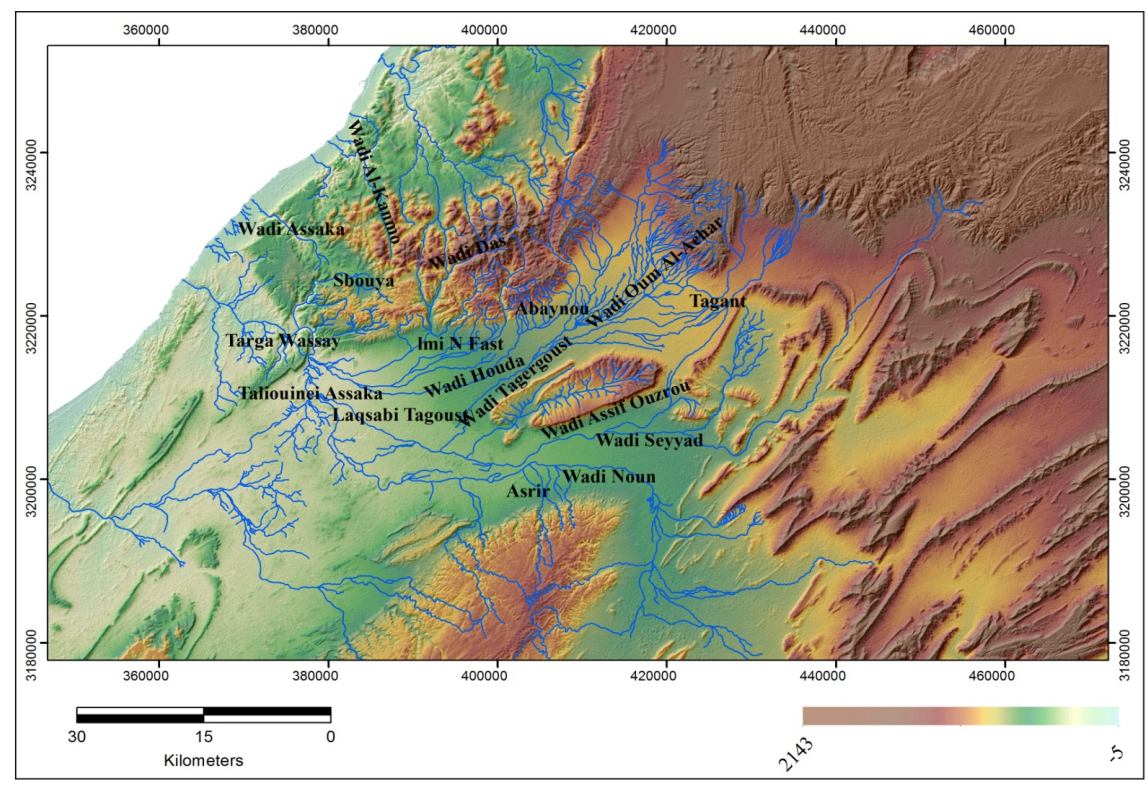

Figure 8. ASTER DEM over the study site. 


\subsection{Landsat-8 0LI Sensor Data}

Since 1972, the Landsat scientific collaboration program between the NASA and USGS constitute the continuous record of the Earth's surface reflectivity from space. Indeed, the Landsat satellites series support more than four decades of a global moderate resolution data collection, distribution and archive of the Earth's continental surfaces [44] to support research, applications, and climate change impact analysis at the global, the regional and the local scales [45]. In February 11, 2013, for the replacement of the Landsat-7 system, the polar-orbiting Landsat-8 satellite was launched, transporting two push-broom instruments: the Operational Land Imager (OLI) and the Thermal Infrared Sensor (TIRS). The OLI sensor collects land-surface reflectivity in the visible, NIR, and SWIR wavelength regions as well as a panchromatic band (Table 1), similarly to the ETM+ sensor. However, the band passes are narrower (Figure 9) than that of the ETM+ in order to minimize atmospheric absorption features [46]. For instance, the OLI NIR spectral band was chosen to avoid the water vapour absorption feature at

Table 1. The Operational Land Imager (OLI) Characteristics (wavelength, SNR = signal to noise ratio).

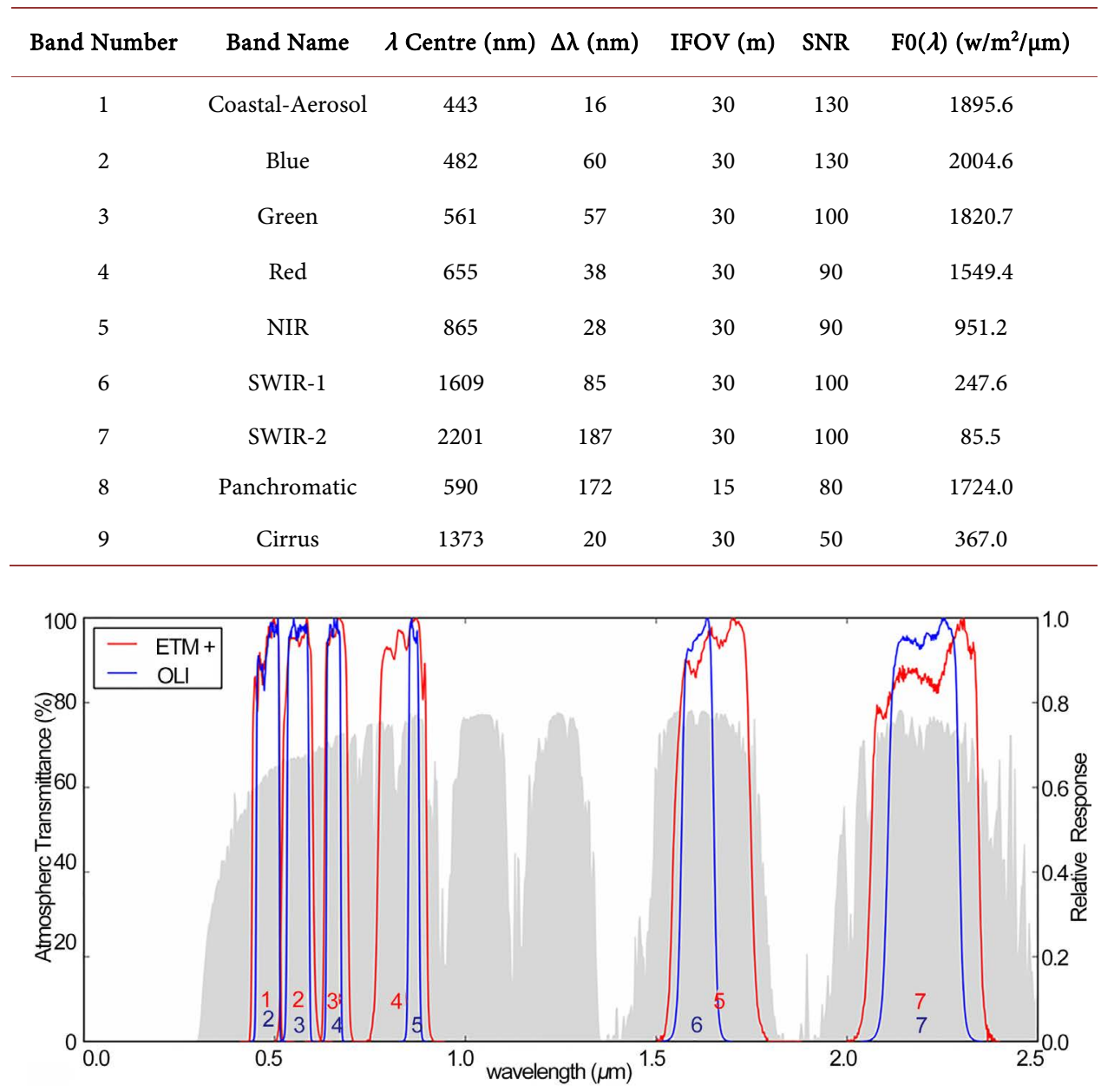

Figure 9. Relative response profile of the OLI Landsat- 8 sensor. 
$0.825 \mu \mathrm{m}$, which was covered with the TM and ETM+ NIR bands. Two new spectral bands have been added: a deep blue visible shorter wavelength (band 1: $0.433-0.453$ $\mathrm{m})$ designed specifically for water resources and coastal zone investigation, and a new SWIR band (9: $1.360-1.390 \mathrm{~m}$ ) for the detection of cirrus clouds (Table 1). Moreover, the OLI design results in a more sensitive instrument, providing improved land-surface reflectivity and information extraction with very less moving parts. With a significant amelioration of the signal-to-noise ratio (SNR) radiometric performance quantized over a 12-bit dynamic range (Level 1 data), products are delivered in 16 bit compared to previous Land sat sensors (TM and ETM+) using only 8 bit [47]. This SNR performance (Table 1) and improved radiometric resolution provide a superior dynamic range and reduce saturation problems associated with globally maximizing the range of land-surface spectral radiance and, consequently, enable better characterization of land-cover conditions [46] [48] [49]. In this research, two raw OLI images were used, the first image was acquired in November 072014 (two weeks before the inundation) and the second image was collected in December 09 2014, eight days after the flood. Note that the bands 1,8 and 9 were not considered in this study.

\subsection{Data Preprocessing}

\subsubsection{Sensor Calibration and Atmospheric Corrections}

Prior to launch, the OLI sensor was subject to rigorous and absolute radiometric and spectral characterization and calibration [49] [50] [51] [52]. However, post-launch absolute calibration is an important step to establish the relationship between at-sensor radiance $\left[L^{\star}(\lambda)\right.$ in $\left.\mathrm{W} / \mathrm{m}^{2} / \mathrm{sr} / \mu \mathrm{m}\right]$, or reflectance $\left[\rho^{\star}(\lambda)\right]$ and the digital numbers [DN $(\lambda)$ ] output for each pixel in the different spectral bands. Indeed, absolute calibration allows the transformation of the digital number $[D N(\lambda)]$, which is measured at the sensor level, into apparent equivalent radiance $\left[L^{\star}(\lambda)\right]$ at the top of atmosphere (TOA), or into apparent reflectance $\left[\rho^{\star}(\lambda)\right]$ at the TOA with a correction for solar zenith angle. Without these operations, the changes caused by artifacts relative to the sensor can be mistakenly attributed to changes in the land use and ground biophysical components. Consequently, errors can propagate in all subsequent steps taken during the image processing, such as spectral indices calculations, multi-temporal analysis, climate change modeling, target classification, etc. [53] [54] [55] [56]. The USGS EROS Center delivers the values of the solar zenith angle, multiplicative and additive rescaling coefficients (gain and off set) in the metadata file for the apparent radiance or apparent reflectance conversion (Table 2).

Furthermore, two processes that are responsible for the modification of the satellite signal, mainly absorption by gases (ozone, water vapour, and carbon dioxide) and scattering by aerosols and molecules [57], dominate atmospheric effects. These phenomena cause an attenuation of the signal in the direction of illumination, but increase the signal in the other directions because of scattering effects. An accurate correction of atmospheric effects requires a priori knowledge of the atmospheric parameters that interfere with the data acquisition during its operation [58]. For the used images, these 
parameters were measured during the passage of the satellite over the study site by the meteorological station located closest to the study site. The Canadian Modified Simulate the Satellite Signal in the Solar Spectrum (CAM5S), based on the Herman radiative transfer code [59], was used for atmospheric parameter simulation. CAM5S simulates the signal measured at TOA from the Earth surface reflecting solar and sky irradiance at sea level, while considering the OLI sensor characteristics, such as the band passes of the solar-reflective spectral bands (Figure 9), satellite altitude, atmospheric condition, atmospheric model, Sun and the sensor geometry, terrain elevation, etc. Consequently, all the requested atmospheric correction parameters were simulated and calculated. They were then used to transform the apparent reflectance at the TOA to the ground reflectance, $\rho_{G}(\lambda)$ using Equation (3). Table 3 summarizes the input parameters for the CAM5S radiative transfer code (RTC). In order to preserve the radiometric integrity of the images, absolute radiometric calibration and atmospheric effects (scattering

Table 2. Multiplicative and additive rescaling coefficients (G: gain and O: offset) for the radiance conversion provided in the metadata file by the USGS EROS Center and used in this study.

\begin{tabular}{|c|c|c|c|c|c|c|c|}
\hline \multirow{2}{*}{\multicolumn{2}{|c|}{ Images }} & \multicolumn{6}{|c|}{ OLI Spectral bands } \\
\hline & & 2 & 3 & 4 & 5 & 6 & 7 \\
\hline \multirow{2}{*}{1} & G & $1.3092 \mathrm{E}-02$ & $1.2064 \mathrm{E}-02$ & $1.0173 \mathrm{E}-02$ & $6.2254 \mathrm{E}-03$ & $1.5482 \mathrm{E}-03$ & $5.2183 \mathrm{E}-04$ \\
\hline & $\mathrm{O}$ & -65.4592 & -60.3201 & -50.8653 & -31.1270 & -7.7410 & -2.6091 \\
\hline \multirow{2}{*}{2} & G & $1.3254 \mathrm{E}-02$ & $1.2213 \mathrm{E}-02$ & $1.0299 \mathrm{E}-02$ & $6.3025 \mathrm{E}-03$ & $1.5674 \mathrm{E}-03$ & $5.2829 \mathrm{E}-04$ \\
\hline & $\mathrm{O}$ & -66.2702 & -61.0674 & -51.4955 & -31.5127 & -7.8369 & -2.6415 \\
\hline
\end{tabular}

Table 3. Input parameters for the CAM5S RTC (ASL: above sea level; GMT: Greenwich Mean Time; ppm: parts per million).

\begin{tabular}{|c|c|c|}
\hline Parameters & Image 1 & Image 2 \\
\hline Terrain elevation (ASL) & \multicolumn{2}{|c|}{$0.755 \mathrm{~km}$} \\
\hline Sensor elevation & \multicolumn{2}{|c|}{$705 \mathrm{~km}$} \\
\hline Time of over-flight (GMT) & $11: 11: 21$ & $11: 11: 14$ \\
\hline Date of over-flight & 07 Nov. 2014 & 09 Dec. 2014 \\
\hline Solar zenith angle (deg.) & 48.357 & 55.156 \\
\hline Solar azimuth angle (deg.) & 156.307 & 156.957 \\
\hline Atmospheric model & \multicolumn{2}{|c|}{ Mid-latitude Summer } \\
\hline Aerosol model & \multicolumn{2}{|c|}{ Continental } \\
\hline Horizontal visibility & $50 \mathrm{~km}$ & $40 \mathrm{~km}$ \\
\hline Ozone content & \multicolumn{2}{|c|}{$0.319 \mathrm{~cm}$-atm } \\
\hline Water vapour & \multicolumn{2}{|c|}{$2.93 \mathrm{~g} / \mathrm{cm}^{2}$} \\
\hline $\mathrm{CO}_{2}$ mixing ratio & \multicolumn{2}{|c|}{$357.5 \mathrm{ppm}$ (as per model) } \\
\hline
\end{tabular}


and absorption) were combined and corrected in one step [60] [61] as follows:

$$
\begin{gathered}
L^{*}(\lambda)=G_{(\lambda)} D N_{(\lambda)}+O_{(\lambda)} \\
\rho^{*}(\lambda)=\frac{L^{*}(\lambda) \cdot \pi \cdot D^{2}}{E s(\lambda) \cdot \operatorname{Cos}(\theta s)}
\end{gathered}
$$

and

$$
\rho^{*}(\lambda)=\overline{\operatorname{tg}}(\lambda) \cdot\left[\rho_{a}(\lambda)+\rho_{G}(\lambda) \cdot \frac{T(\lambda) \theta_{s} \cdot T(\lambda) \theta_{v}}{1-\rho_{G}(\lambda) \cdot S}\right]
$$

where:

$$
\begin{aligned}
& \left.L^{\star}(\lambda)=\text { Apparent equivalent spectral radiance at TOA [Watts }\left(\mathrm{m}^{2} \operatorname{srad}^{*} \mu \mathrm{m}\right)\right], \\
& G_{(\lambda)}=\text { Radiance multiplicative rescaling factor from the metadata (gain), } \\
& O_{(\lambda)}=\text { Radiance additive rescaling factor from the metadata (offset), } \\
& D N_{(\lambda)}=\text { Digital number values, } \\
& \rho^{\star}(\lambda)=\text { Apparent reflectance at TOA, with a correction for solar zenith angle, } \\
& \rho_{a}(\lambda)=\text { Atmospheric at-sensor reflectance, } \\
& \rho_{G}(\lambda)=\text { Ground reflectance, } \\
& \overline{\operatorname{tg}}(\lambda)=\text { Average total gaseous transmittance, } \\
& T(\lambda) \theta_{s}=\text { Total descending scattering transmittance, } \\
& T(\lambda) \theta_{v}=\text { Total ascending scattering transmittance, and } \\
& \mathrm{E}_{S}(\lambda)=\text { Solar irradiances } \\
& \theta_{s}=\text { Solar zenith angle, } \\
& \theta_{V}=\text { Sensor zenith angle, } \\
& S=\text { Spherical albedo. }
\end{aligned}
$$

\subsubsection{Geometric and Topographic Rectifications}

During the 90-day period following the OLI launch, three types of geometric calibrations were performed on-orbit including updating the OLI-to-spacecraft alignment knowledge, refining the alignment of the sub-images from the multiple OLI sensor chips, and refining the spatial alignment of the OLI spectral bands. The results showed that the considered aspects of geometric performance met the system accuracy requirements [62]. However, one of the remote sensing objectives is to provide quantitative information for producing conform and standard cartographic documents and deriving digital data files compatible with GIS databases. Within this framework, rigorous geometrical and topographical corrections are essential [63]. The provided OLI data as delivered from the USGS EROS Center are geometrically corrected and registered to the WGS-84 geodetic reference. Nonetheless, a second-degree polynomial function cannot eliminate the distortions caused by the relief and the shadow impact, especially in the Guelmim study area with Atlas Mountains peaks of more than $2100 \mathrm{~m}$. Indeed, the intersection of the FOV sensor with the terrain altitude variation can probably produces pixels with variable size following the slope and aspect (moderately negligible for OLI due to its relatively narrow FOV), and varying spectral signature from uniform and similar targets [64]. In addition, the association of the topographic variation with the illumination geometry significantly contributes in spectral signature variation over the 
same target. For correcting terrain relief effects, it is necessary to have an altitude value for any point in the image, namely a DEM. The sampling step of this DEM must be of the image pixel size or higher spatial resolution to provide an ortho-image with good precision [63] [65] [66]. In this study, an ortho-rectification was conducted using ASTER-V2.1 GDEM with a $30 \mathrm{~m}$ pixel size and the Rational-Function model implemented in the Ortho-Engine module of PCI-Geomatica [67]. Topographic attributes, such as altitude, slope, aspect, and sky view, integrated into the ortho-rectification approach, were extracted from the DEM [68].This step enabled corrections of the parallax effect at the spatial arrangement of pixels along track, disruptive effects caused by shadow and topographic variability, as well as the residual atmospheric artifacts caused by altitude variability. Additionally, it allowed the integration of derived maps into a GIS for analysis and 3D visualization. To preserve the image radiometric integrity, geometric corrections have been combined into a single step with the correction of topographic effects [68].

\subsection{Data Processing}

\subsubsection{Coloration Index}

Colour is an important criterion for soil characterization; it results from its mineralogical composition and organic matter content [69] [70]. The latter gives the soil a dark colour, while the iron oxides-hydroxides and the calcium carbonates cause a red colour and a clear and bright colour, respectively [71]. Thus, the presence of outcrops of gypsum and limest one crusts causes little soil coloration in arid regions [72]. The erosion process can obviously deteriorate the soil surface horizon rich in organic matter, hence, making the soil more clear and bright or completely destroy the floor and flush the bedrock surface whose colour can be totally different from the intact soil [73]. Several studies have shown a strong correlation between the soil colour sand their reflectance in the visible bands [74] [75] [76]. Based on this correlation, Escadafal et al. [11] developed the coloration index (CI), which is a simple normalized ratio of red and blue bands. The reflectance in this spectral region is greatly affected by the iron oxide absorption phenomenon (hematite and/or goethite). Many studies have underlined the advantage of the CI to characterize the status of land degradation, particularly in arid and semi-aridregion [2] [11] [77] [78], especially when the red band is substituted by the NIR band [3] [13] [73] as follows:

$$
C I=\left(\rho_{\text {nir }}-\rho_{b}\right) / \rho_{b}
$$

where $\rho_{\text {nir }}$ is the reflectance in NIR band (OLI-5) and $\rho_{b}$ is the reflectance in the blue band (OLI-2).

\subsubsection{Form Index}

To characterize soil types and levels of their erosion and degradation, the shape of their spectral signature curves can be in formative [73]. It is determined by the reflection and absorption properties of its components [69], including organic matter, iron oxides, clay minerals and carbonates whose presence are an indicator of the soil development. 
Baumgardner et al. [15] found that the spectra of the developed soils have absorption bands, which are an indicator of certain soil development formation (important organic matter content, iron oxide and clay mineral presence). These soils are characterized by relatively low levels of reflectance. While high degraded soils would present high reflectance levels (presence of carbonate material and absence of iron oxide). This variability in reflectance is due to the presence or absence of iron oxides and organic matter absorption bands. Based on this spectral variability in the visible, Escadafal et al. [11] developed the form index (FI) to discriminate among different soil degradation levels in arid land.

$$
F I=\left(2 \cdot \rho_{r}-\rho_{g}-\rho_{b}\right) /\left(\rho_{g}-\rho_{b}\right)
$$

where $\rho_{r}$ is the reflectance in red band (OLI-4) and $\rho_{g}$ is the reflectance in green band (OLI-3).

This index has been used in various studies to map the different levels of land erosion and degradation, particularly in arid and semi-arid regions. Moreover, they reported that the integration of the SWIR bands into the FI equation has the potential to improve its ability to detect accurately soil erosion and land degradation classes [2] [3] [13] [78].

\subsubsection{Brightness Index}

In addition to the colour, the spectral properties of the soil are strongly related to its brightness variation [10] [79]. This variability allows the identification of the global reflectance of a soil and leads Escadafal and Bacha [11] to develop the brightness index (BI) exploiting the visible and NIR spectral domains. Mathieu and Pouget [80] proposed another version of the BI to map the soils in Chile using only the visible bands. According to Ghram-Messedi and Detaître [81], the BI allows good discrimination between vegetation cover and the minerals, especially when the soil is dry and bright (e.g., silica-sand, limest on enodules, gypsum crust). This index is strongly correlated with the iron oxide content in the sand dunes of a semi-arid environment [82]. However, its accuracy varies with the shadow effects [83] and the soil moisture content, i.e., the increase in water content is accompanied by a decrease in the purity of the luminance, which is relative to the colour brightness reduction [84] [85]. Escadafal and Bacha [11] and Minouni et al. [3] reported that the integration of the NIR band in the calculation of this index provides significant discrimination of bright colour soils, which contain sandstone and are in general calcareous and susceptible to erosion risk. The BI is calculated as follows:

$$
B I=\sqrt{\left(\rho_{\text {nir }}^{2}+\rho_{\mathrm{r}}^{2}+\rho_{g}^{2}\right)}
$$

\subsubsection{Intensity, Hue and Saturation}

In addition to the aforementioned indices, FI, CI and BI, soils can also be characterized by the intensity (I), hue (H) and saturation (S) of their colour [86]. These three variables derived by transformation of the three visible bands are corresponding to the brightness, spectral dominance, and the purity of the colour, respectively [18] [87]. Es- 
cadafal et al. [11] and Haboudane et al. [13] have shown that the "I" is an important discriminating factor among various levels of soil degradation. Moreover, it was proven that the " $\mathrm{H}$ " is a critical parameter for soil identification and mapping [88]. According to Madeira et al. [89] and Fontes and Carvalho [90], the " $H$ " characterizes well the hematite and describes adequately the hematite/goethite ratio. Its values are also independent of illumination and are related only to the shape of the spectral signatures [87]. Therefore, it can be used for the identification and discrimination of soils and lithological formations [88]. The "S" quantifies correctly the iron oxides in the soil [90] and discriminates the different rock types [91]. Frequently, the integration of "I-H-S" is used in the optical and radar data fusion for soil and rock discrimination [18] [92] [93]. In addition, this integration significantly characterizes soil degradation states and provides important results in terms of geomorphologic and geologic mapping [94]-[100]. In the literature, three methods have been developed to transform spectral bands to the "I-H-S" space: hexagonal [101], double-hexagonal [102] and cylindrical [103]. According to Mimouni et al. [3], the cylindrical transformation, integrating the NIR and SWIR bands, provides relevant and accurate information about soil erosion and degradation in arid and semi-arid environments. This transformation can be calculated as follows:

$$
\begin{gathered}
{\left[\begin{array}{c}
I \\
v_{1} \\
v_{2}
\end{array}\right]=\left[\begin{array}{ccc}
\frac{1}{\sqrt{3}} & \frac{1}{\sqrt{3}} & \frac{1}{\sqrt{3}} \\
\frac{-1}{\sqrt{6}} & \frac{-1}{\sqrt{6}} & \frac{-2}{\sqrt{6}} \\
\frac{-1}{\sqrt{2}} & \frac{1}{\sqrt{2}} & 0
\end{array}\right] \times\left[\begin{array}{c}
\rho_{\text {SWIR }}-1 \\
\rho_{\text {SWIR }}-2 \\
\rho_{\text {nir }}
\end{array}\right]} \\
H=\tan ^{-1}\left(\frac{v_{1}}{v_{2}}\right)
\end{gathered}
$$

and

$$
S=\sqrt{v_{1}^{2}+v_{2}^{2}}
$$

where $\rho_{\text {SWIR }}-1$ is the reflectance in SWIR-1 (bandOLI-6) and $\rho$ SWIR -2 is the reflectance in SWIR-2 (bandOLI-7).

\subsubsection{Principal Component Analysis}

Principal component analysis (PCA) is a mathematical transformation based on the image covariance analysis or the correlation matrix of several spectral bands [64]. It is a technique that allows the reorganization of the data so that they are not correlated and maximizing the signal-to-noise ratio [104]. When applied to data in N-dimensions, it concentrates almost all of the information (90\%) in the first two or three components [105]. Thus, the first component contains information relating to the maximum of the variance, the second contains the information on the next variance, etc. The process is iterative up to obtaining the $N^{\text {th }}$ and final component [106]. Obviously, when multispectral data acquired by the Landsat sensors are processed, the first three components are the most useful and informative [105]. According to Rajaonarison et al. [107] the same components were used to assess the degree of the influence of natural factors (to- 
pography, geology, soils, land use, etc.) and the human impact on the water erosion phenomenon. Moreover, other studies have shown that the PCA derives new and critical information related to eroded and degraded areas [19] [20] [21] [108] [109]. Dhakal et al. [110] demonstrated the utility of the PCA for detection and mapping of areas associated with flood and erosion caused by a heavy rainfall using multi temporal TM Data. Consequently, the first three PCA were integrated in this research to characterize the flood-storm impact on the land erosion and sediment accumulation.

\subsubsection{Vegetation Index}

In semi-arid and arid environments, monitoring the scattered vegetation cover dynamics is a regional indicator of water erosion and desertification processes. If the land use is considered, soil erosion and land degradation increases when the soil has slight vegetation cover. This can be quantified from remotely sensed imagery or by inverse radiative transfer modeling, using vegetation indices [111]. These are relatively correlated with vegetation coverage and the green biomass [112]. The Normalized Difference Vegetation Index (NDVI) is the most popular and the most used index [113], but it is very sensitive to the atmospheric conditions and the soil background, especially in arid and semi-arid environments where the vegetation cover is sparse [9] [10] [114]. To minimize these effects and to adequately describe the dynamic range of the soil-vegetation system, the TDVI was developed [115]. This index provides satisfactory results in different applications using remotely sensed data [3] [116]. It was considered in this study and combined with the soil indices to quantify and analyze the soil erosion and degradation classes.

$$
T D V I=1.5 *\left[\left(\rho_{\text {nir }}-\rho_{r}\right) / \sqrt{\rho_{\text {nir }}^{2}+\rho_{r}+0.5}\right]
$$

\subsubsection{Soil and Vegetation Moisture Content Indices}

Soil moisture conditions and vegetation water content at different times (i.e. between droughts and floods periods) can change extremely. The monitoring of surface water related to the impact of inundation and the mud floods is crucial for soil erosion, land degradation, sediment quantification and hydrological cycle. Soil reflectance variations due to moisture content change significantly between the $0.4 \mu \mathrm{m}$ and $2.5 \mu \mathrm{m}$ spectral domains [117]. Indeed, the bare soil spectral signature decreases as soil moisture content increases due to a darkening of the soil surface, as well as of the fulfillment of empty pores by water [69] [118]. This spectral variability has been used to develop a soil moisture content estimation and mapping approach [119] [120]. Gao [22] proposed the Normalized Difference Water Index (NDWI) for vegetation liquid water estimation from space, exploiting the NIR $(0.86 \mu \mathrm{m})$ and SWIR $(1.24 \mu \mathrm{m})$ bands. In fact, absorption by vegetation liquid water near $0.86 \mu \mathrm{m}$ is negligible, and the weak liquid absorption at $1.24 \mu \mathrm{m}$ is present. The multiple scattering at the canopy then enhances the water absorption and, consequently, the NDWI became more sensitive to changes in liquid water content of vegetation canopies. Moreover, the used bands $(0.86 \mu \mathrm{m}$ and $1.24 \mu \mathrm{m})$ are both located in atmospheric windows, where water vapour absorption is 
very small and atmospheric aerosol scattering effects are insignificant. This index was also used for soil moisture content mapping after flash flood periods [24] [25] [26]. As well, Xiao et al. [121] concluded that NDWI could be used for detecting flooding over rice fields in China. Furthermore, a new moisture index, the Normalized Multi-band Drought index (NMDI), was proposed by Wang and $\mathrm{Qu}$ [23] for remote sensing of both soil and vegetation water content mapping using three bands in the NIR and SWIR $(0.86 \mu \mathrm{m}, 1.64 \mu \mathrm{m}$ and $2.13 \mu \mathrm{m})$ :

$$
N D W I=\left(\rho_{\text {nir }}-\rho_{\text {swir-2 }}\right) /\left(\rho_{\text {nir }}+\rho_{\text {swir-2 }}\right)
$$

and

$$
N M D I=700 *\left(\rho_{\text {nir }}-\rho_{\text {swir }-1}+\rho_{\text {swir }-2}\right) /\left(\rho_{\text {nir }}+\rho_{\text {swir }-1}-\rho_{\text {swir }-2}\right)
$$

Chen et al. (2014) demonstrated the utility of this index with multi-sensor data fusion for monitoring surface soil moisture variations in time during dry seasons in Central America. The synergy of these two indices with those discussed previously was also considered in this research.

\section{Results Discussion and Conclusions}

\subsection{Topographic Profiles Analysis}

The study site has two main geomorphologic units, the limestone plateau of the Anti-Atlas and quartzite ridges, which is limited by the Atlas mountains (in the N, S, E and W) as a natural barrier (Figure 7 and Figure 8). It is characterized by broader valleys and depressions (feijas) surrounded by hills with heights varying from $153 \mathrm{~m}$ to $2060 \mathrm{~m}$ (Figure 10) and steep slopes varying between $9.5^{\circ}$ to $26^{\circ}$, which are converging towards the interior of the Guelmim plain. The topography of this plain is classified into seven classes whose altitude range vary significantly between $200.0 \mathrm{~m}$ to $573.5 \mathrm{~m}$, starting from northeast to southwest with approximately $373.5 \mathrm{~m}$ height difference. This morphology leads to water retention in the case of rainstorm and, consequently, contributes to the risk of inundation. Figure 11 illustrates three topographic profiles; two from the NE to SW (B and C) and one from NW to SE (A), showing a natural barrier, which leads to water retention in case of high precipitation intensity. Thus, it is one of the factors supporting the risk of flash floods. The profile "A" in Figure 11 shows an appropriate morphology for runoff water catchment with a depth of $250 \mathrm{~m}$ between two mountains (Jebel Ifni and Jebel Taissa), which surround the plain in that direction. Figure 11(B) illustrates the topographic profile " $\mathrm{B}$ ", showing the area prone to inundation. It can be seen that the slope orientation and direction of the Guelmim watershed are facing the center of the plain. As well, a hill in the East forms a natural barrier with a denivelation of approximately $100 \mathrm{~m}$, which creates a natural basin promoting the accumulation of water and sediments over an $14 \mathrm{~km}$ distance. The topographic profile "C" (Figure 11) starting at the foot of Guelmim city (NE-SW) illustrates a very strong slope $\left(26^{\circ}\right)$, which ends on a terrain with concave morphology forming a natural basin. This basin facilitates the accumulation of storm flood, thereby concentrating runoff water, sediment and mud load. 


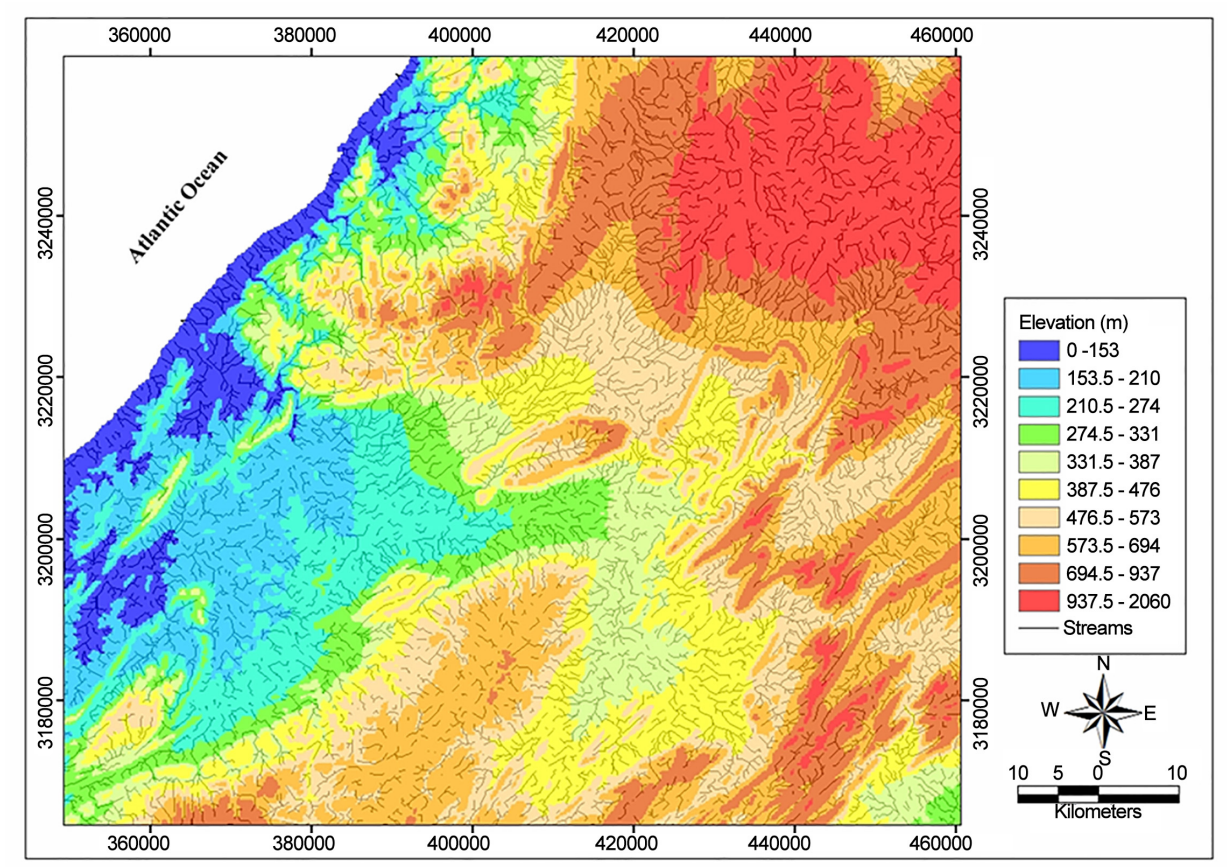

Figure 10. Elevation map over the study site.

The highest altitude values (between $500 \mathrm{~m}$ and $2100 \mathrm{~m}$ ) with the steep slopes and ridges (corresponding to "feija" schist and soft Quaternary deposits), representing the streams and drainage system, depressions and broader-valleys are related to a relatively high slope gradient $\geq 20^{\circ}$ (Figure 8, Figure 10 and Figure 11). They contribute significantly to the erosion's aggressiveness associated with a significant degree of sediment transportation, and land degradation risk process. Hard rocks, such as Precambrian quartzite, Adoudounian limestone and dolomite, Ordovician quartzite and sandstone, and Georgian black limestone, characterize these zones (Figure 7). The lowest altitude values represent relatively flat areas with a low slope $\left(\leq 4^{\circ}\right)$ in the NE-SW direction, which is the hydrographic network direction. In addition, morphological factors influence the susceptibility to flooding and sediment deposition and accumulation, because water tends to flow and accumulate in response to gradients in gravitational potential energy. In general, these profiles demonstrate clearly that rainfall and topography are the major contributing factors to flash flooding and catastrophic inundation in the study area. The runoff waterpower delivers vulnerable topsoil and contributes strongly to the erosion and land-degradation process after a flood-storm in the Guelmim basin. It then transports soil material and sediments to the plain through natural action, i.e., water power and gravity. As illustrated by the photos in Figures 1-3, which were acquired during the same day of the flood storm, the water colour was dark red because of its turbidity as it was very rich with sediments and eroded particles. In addition, the classroom of a primary school was filled with mud as shown in Figure 2 after the water retreated. Certainly, the role of the lithology associated with the terrain morphology is decisive in the erosion risk and land degradation in this region. These observations are 

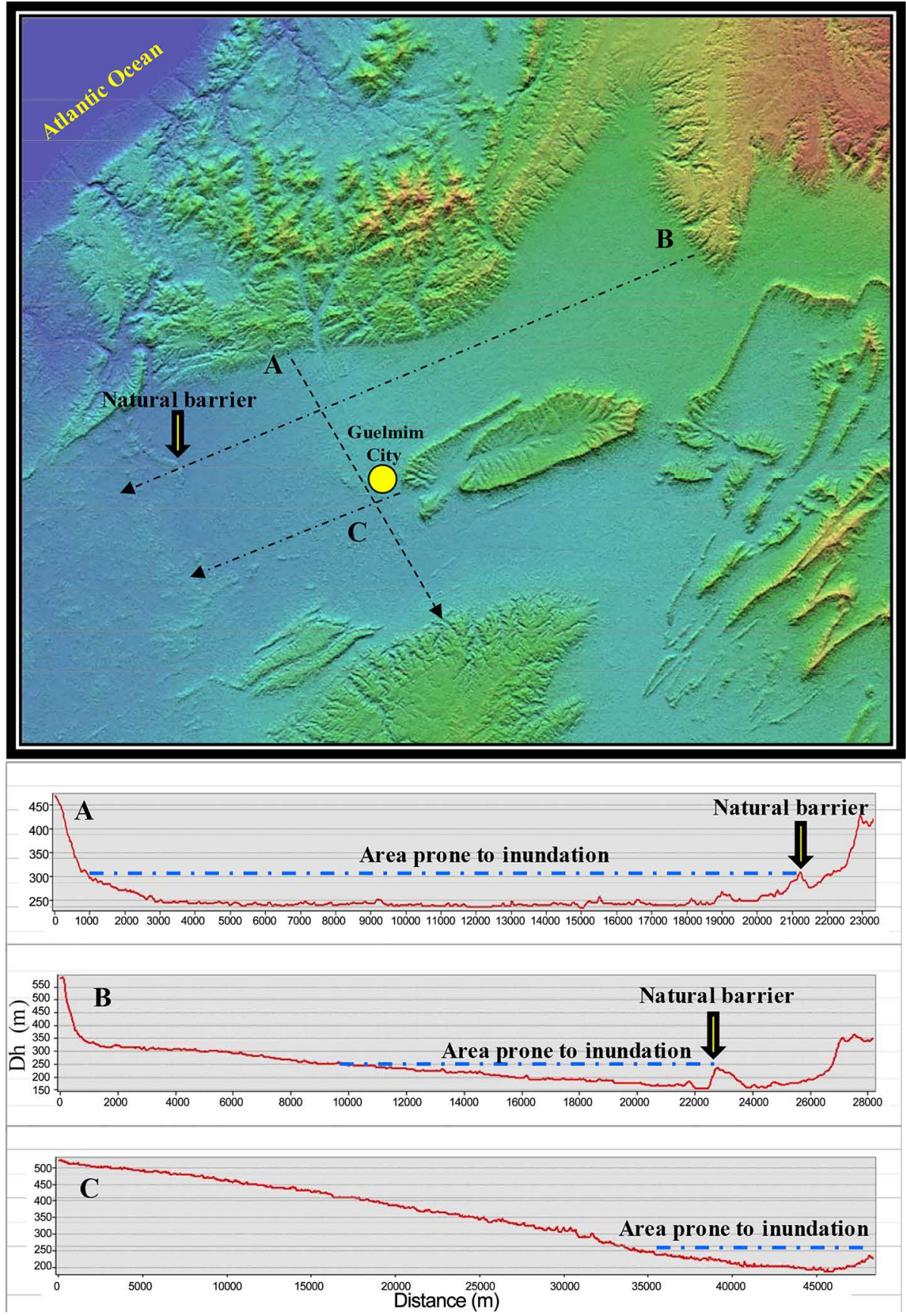

Figure 11. Three topographic profiles, from the NW to SE (A) and from the NE to SW (B) and (C), visualizing the natural barrier which leads to water retention.

in agreement with the results presented by Marchi et al. [122], in which they characterized the extreme flash floods and implications for flood risk management in Europe.

\subsection{Spectral Indices}

In this research different spectral indices were considered, and were grouped into four classes. Class of vegetation and soil moisture indices (TDVI, NDWI and NMDI); class 
of indices based on the soil reflectance spectra (FI, CI and BI). Class of indices that characterize the soil degradation based mainly on the colour intensity and purity (I, $\mathrm{H}$ and S). Finally, the soil condition indicator related to eroded class and its occupation using PCA spectral space. Before the analysis of different combinations of all these considered indices and their contribution for soil erosion and sediment accumulation assessment, the vegetation cover density was first analyzed, and the soil moisture before and after the flood storm in the study area.

Figure 12 illustrates the geographic location and density of vegetation cover in the study area before the flood-storm using TDVI. As anticipated previously, the vegetation cover is very scars in the middle of the Guelmim plateau, except some spots (in green colour) representing small agricultural fields and oases with palm trees, as well along the river bed (consequence of climate change impact and deforestation in the region). At the top of the Mountain, a relative high grass and shrub density can be observed, because this high-altitude region benefits from a mild oceanic climate (near to the coast) and the dew, which irrigate significantly this vegetation. Only the TDVI before flooding is presented here, because after flooding it showed similar patterns except a very modest increase of herbaceous vegetation density in high-altitude areas. Despite the fact that, generally, a vegetation index is not helpful for flood impact assessment or sediment accumulation estimation, TDVI was integrated anyway with other indices to analyze its potential for the discrimination between soil erosion classes. Furthermore, compared to the NMDI, the NDWI shows its usefulness in this study before and after the flood-storm and we will discuss thereafter.

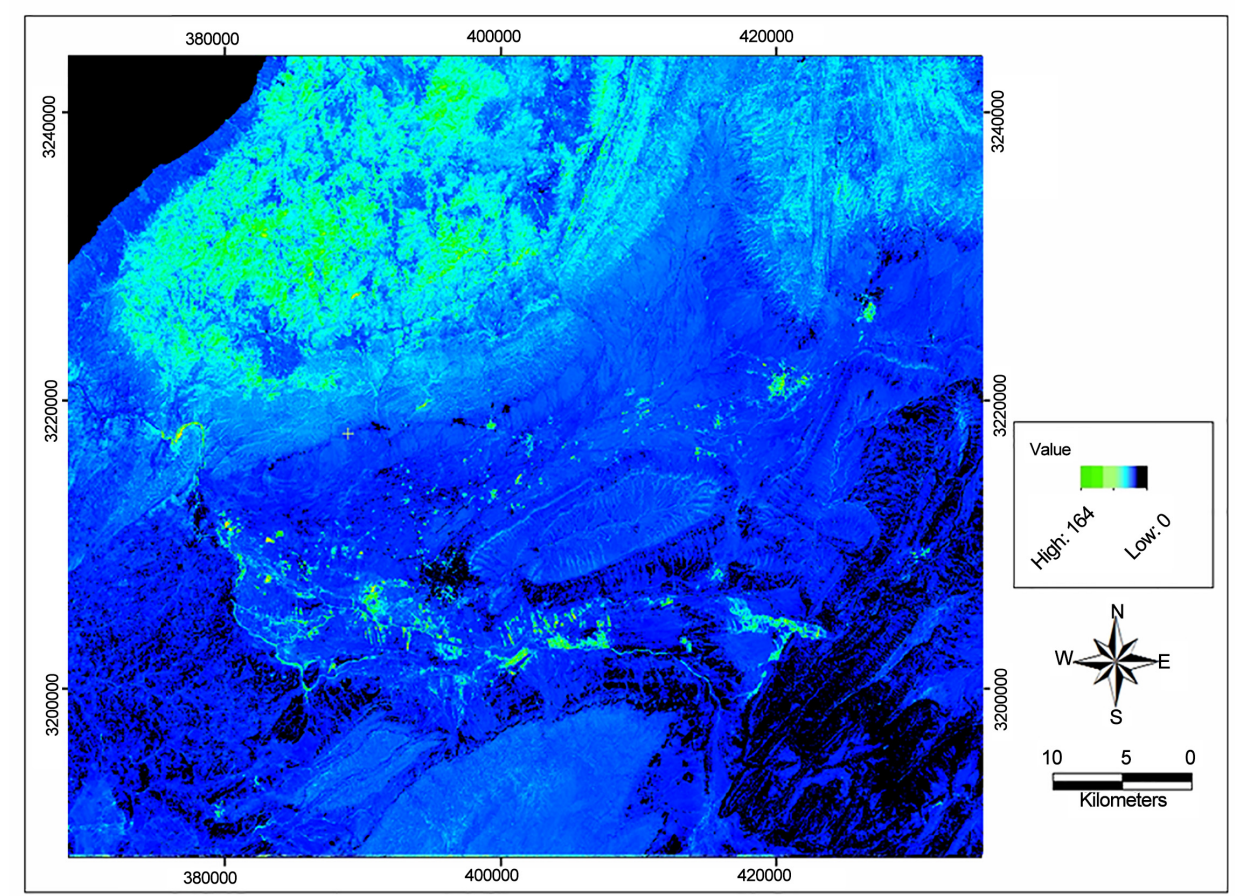

Figure 12. Transformed Difference Vegetation Index (TDVI) map before the flood-storm. 
Figure 13 illustrate Soil Moisture and Ocean Salinity (SMOS) satellite data acquired before, during and after the flood-storm, it shows the soil moisture variability over the Guelmim region [123]. In fact, we see that soil moisture increased from $4 \%$ in November 19 to $72 \%$ in November 22; then from $40 \%$ in November 25 to $74 \%$ in November 29. It can also be observed that the peaks marked these dates, which were followed with succession periods of rain maintaining high soil-moisture conditions (Figure 13). These results are in agreement with NDWI outcome before and after the flood-storm named NDWI-1 and NDWI-2 for further use in this paper, respectively. Figure 14 shows the spatial distribution of water content in soil and vegetation cover using NDWI-1 before the flood-storm (November 07). Firstly, it can be seen that an excellent agreement exists between this index and the derived vegetation cover map generated with TDVI. The moisture (or water content) is highlighted only on the vegetation cover spots, while the soil moisture is approximately near to $0 \%$ as the soil was completely dry. Secondly, the SMOS pixel value corroborates this finding, because Figure 13 shows a moisture value near to $10 \%$ during the November 7 . This SMOS moisture value is acceptable and logic, because it is the average within one pixel ( $25 \mathrm{~km}$ by $25 \mathrm{~km}$ ) covering the Guelmim area, including dry soil and humid vegetation cover. Nevertheless, the derived NDWI-2 map ( 8 days after the flood) as presented in Figure 15 shows different soil moisture classes. This map highlighted the high moisture content in vegetation cover, ravines and water streams, riverbeds, alluvial and dejection cones, down-slopes, and finally the Guelmim plain. These good results corroborate the SMOS value ( $23 \%$ ) obtained by Sairi et al. [123], as well those obtained by Bannari et al. [124] based on hydrological indices derived from the DEM. Concerning the NMDI, this index was not able to reflect the soil and vegetation moisture content accurately as NDWI, especially before the floods. However, after flood when the soil and vegetation were saturated with water, NMDI was able to reproduce similar results to NDWI. In this paper, only the NDWI results were presented because this index describes correctly the soil moisture content independently from the soil or rock characteristics and the vegetation cover density or water content (before and after flood-storm).

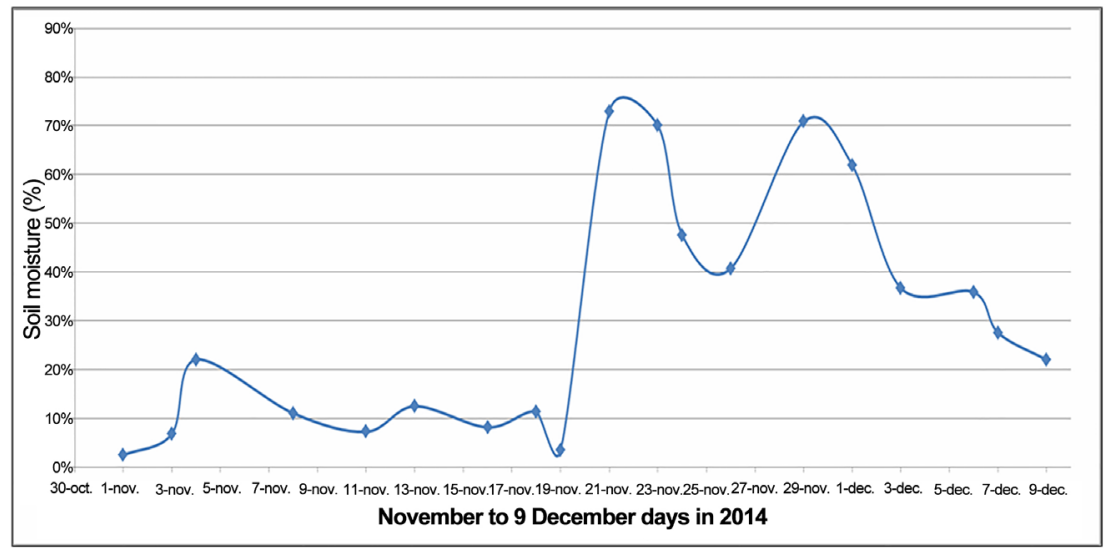

Figure 13. Soil moisture variability for the Guelmim region from 1 November to 9 December 2014 using Soil Moisture and Ocean Salinity (SMOS) satellite data [123]. 


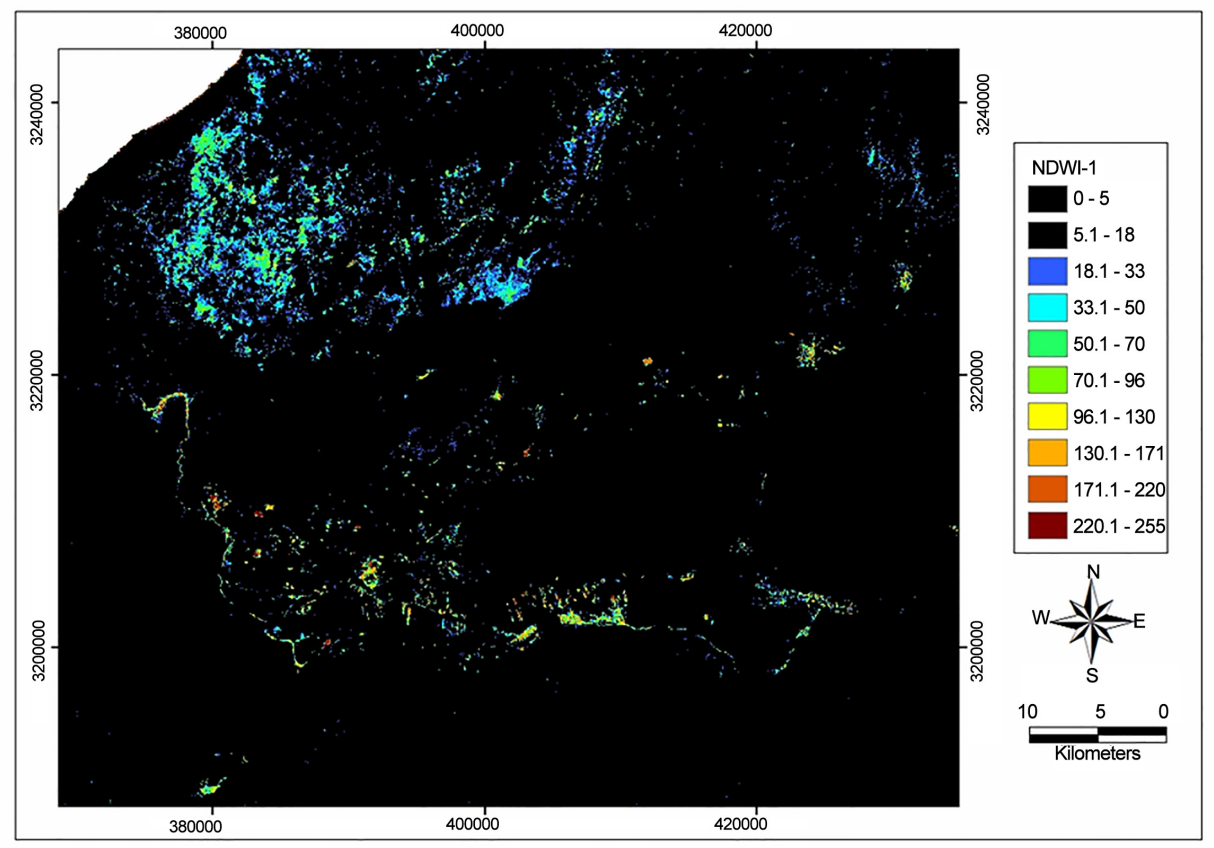

Figure 14. Normalized Difference Water Index (NDWI-1) before the flood-storm.

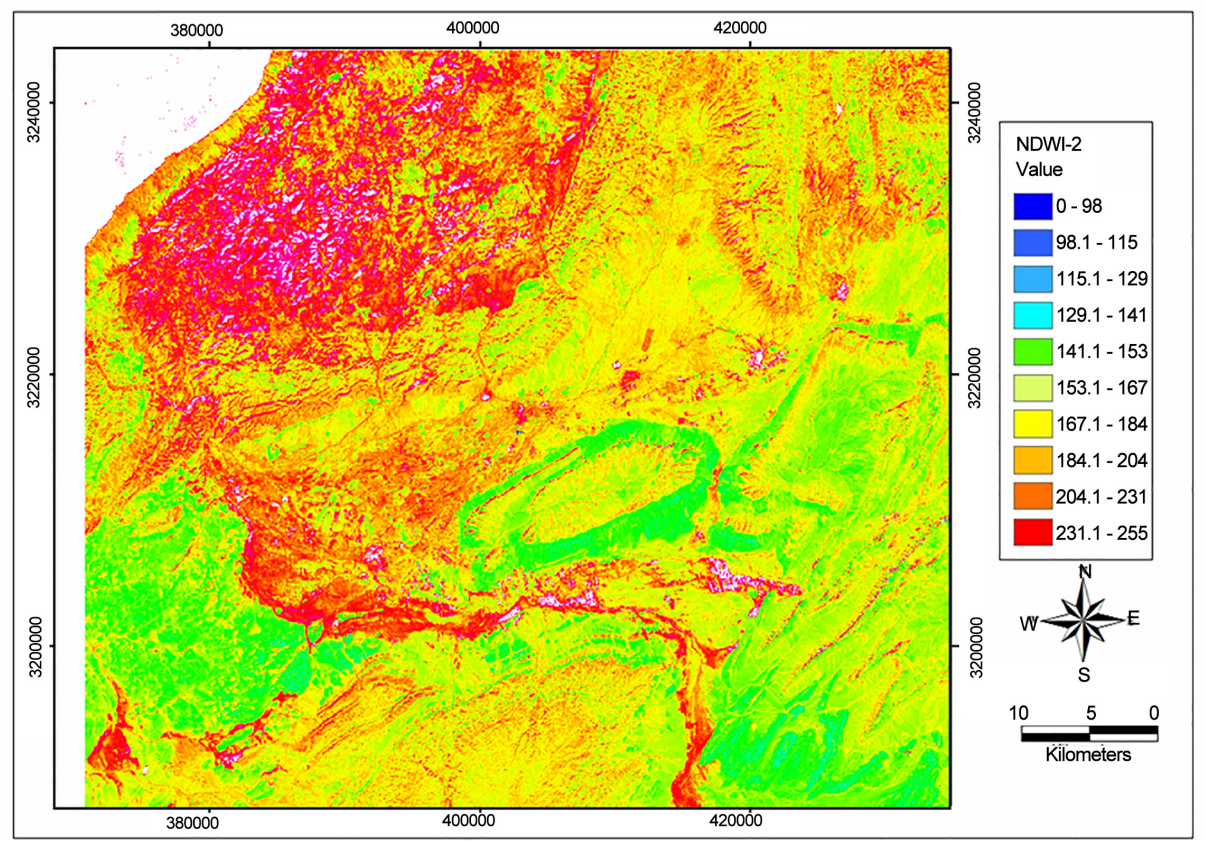

Figure 15. Normalized Difference Water Index (NDWI-2) after the flood-storm.

Because the "I", " $\mathrm{H}$ " and " $\mathrm{S}$ " are important criteria for soil erosion status characterization, only the visible bands, as recommended by Escadafal et al. [86], were used in the beginning, considering the cylindrical transformation as recommended by Mimouni et al. [3]. This processing enhances the image colour in the three-dimensional spectral space using the Munsell-colour chart [103] [125]. The obtained results show that al- 
though the visible domain is informative about the soil spectral variability according to their colours, the NIR and SWIR (SWIR-1 and SWIR-2, see the rage wavelengths in Table 1) regions are more informative on the soil status. Because in these spectral ranges, the power of soil colour discrimination is combined with pedological materials (absorption features characterizing the surface soil category). Indeed, the derived "I" and " $H$ " allow a significant discrimination between various rock types and soil erosion and degradation levels. Nevertheless, the " $H$ " showed exceptional results for lithological formation discrimination and soil classes' characterization, and adequately describes the hematite and goethite. These outcomes are in agreement with other scientists' findings [13] [88] [89] [90]. After this investigation step, more than 100 colour composite combinations have been analyzed in the RGB (Red-Green-Blue) spectral space in PCIGeomatica's image processing system [67] considering all the selected and used indices: CI, FI, BI, I, H, S, NDWI, NMDI, TDVI, PCA-1, PCA-2 and PCA-3. Amongst the entire analyzed and compared combinations, only four attracted the attention according to their power to discriminate different levels of soil erosion in various land-use classes. The first combination considers the FI, BI and NDWI colour composite, which is shown in Figure 16(a) and Figure 16(b). The second one considers the intensity "I", NDWI and NMDI, which is illustrated in Figure 17(a) and Figure 17 (b). The third and fourth combinations consider "S", NDWI and NMDI and PC-1, PC-2 and PC-3, respectively. However, these last two combinations provide a similar spectral behaviour to the first two colour composites. Therefore, the analysis focused only on the first two combinations.

Figure 16 and Figure 17 illustrate the maps of the two retained combinations, which are derived with a simple and rapid way. The $3 \mathrm{D}$ visualisations consider a five-time vertical exaggeration in ArcGIS environment. They discriminate among several land-use classes, but the focus was only on the desired thematic classes, which are related to land erosion and sediment accumulation caused by runoff after the flash-flooding storm. Within this context, the considered classes are vegetation cover, mud and sediments accumulation, and very low, medium and high soil erosion risk. The shadow-effect class is completely absent, because the images were very well ortho-rectified. For validation purposes, the acquired photos during the flood-storm (Figures 1-3), lithological map (Figure 7), and geological map (Figure 18) were used.

Figure 16 demonstrated the powerful synergy between the FI, BI and NDWI indices to discriminate correctly among rocks and soil classes as well vegetation cover and the mud and sediment direction and accumulation. The vegetation cover is well mapped (blue colour) in the top of the mountains and following the river bed. The geological classes are very distinct, showing uniform belts from the Guelmim plateau centre to the four geographical directions (N, S, W and E). The soil moisture content, soil erosion risk areas, and recent sediment transport and accumulation due to the flood are perfectly highlighted based on the spectral proprieties of these indices. The mud deposit and sediments transport direction and accumulations are visible in the purple colour. The very low erosion-risk class (green colour) characterise the volcanic rocks, while the 


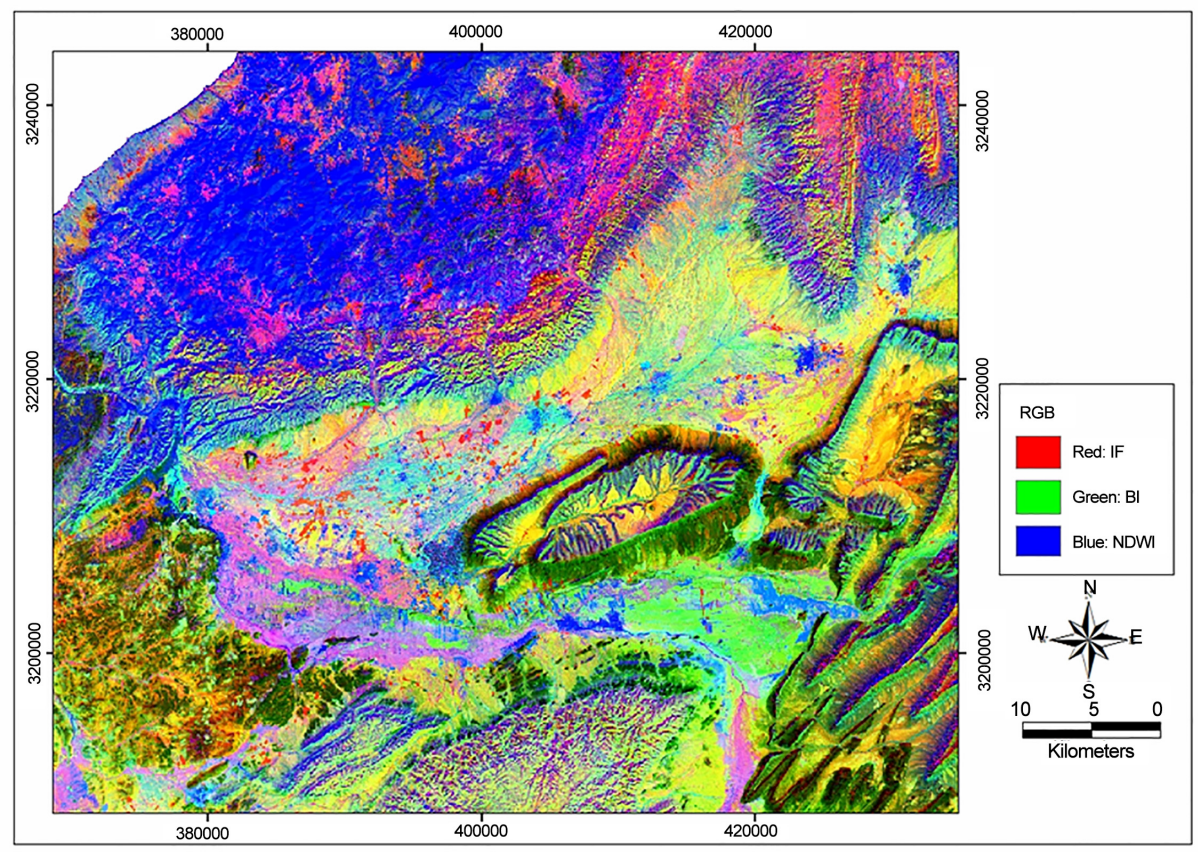

(a)

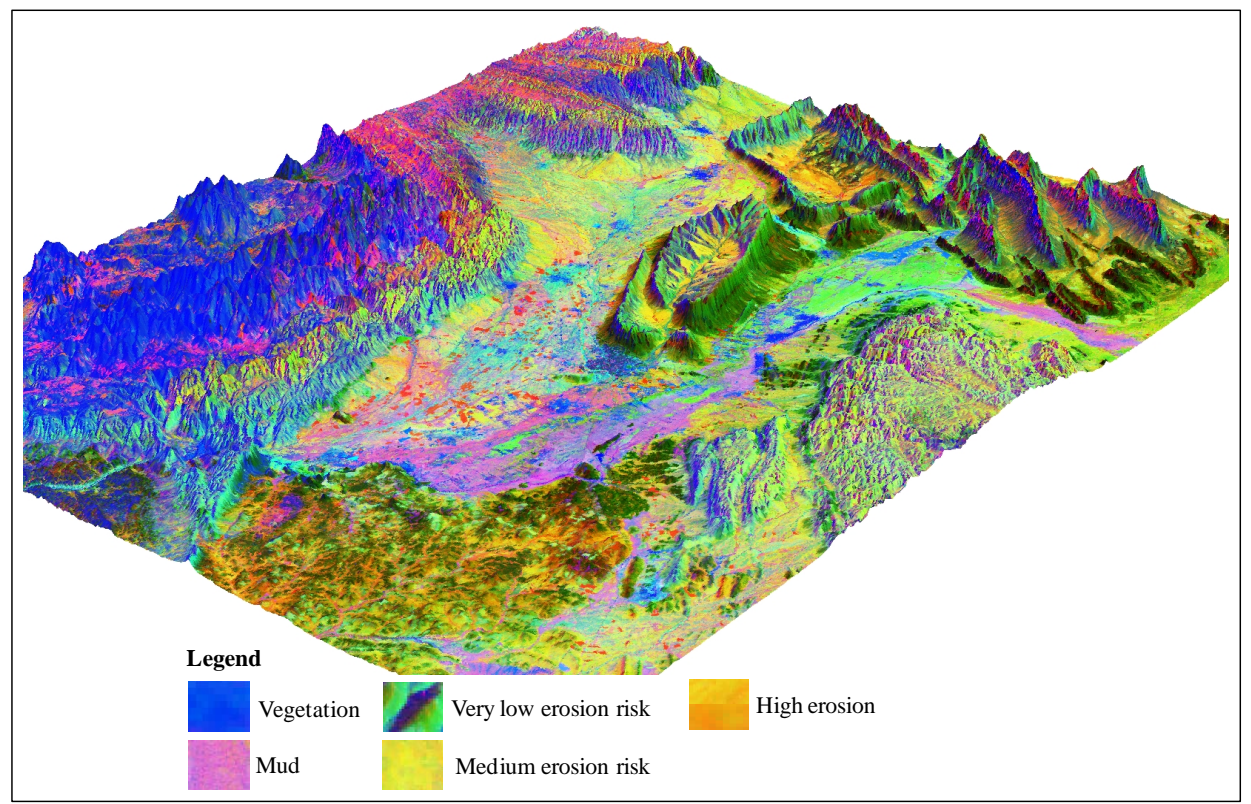

(b)

Figure 16. Map derived from the colour composite obtained by the encoding form index (FI) in red, brightness index (BI) in green, and normalized difference water index (NDWI) in blue (after storm).

medium erosion risk class is shown in yellow located at the foot of the mountain with intermediate to low slopes near the dejection cones and water streams. The high levels of erosion risk and aggressiveness zones in dark beige-yellow are encountered in the valleys and over areas with steeper slopes. Consequently, the valleys are zones of flow 
accumulation receiving the contribution of large upslope drainage areas, thereby allowing high rates of erosion. In addition, the 3D representations reflect the real spatial distribution of the flash-flood storm impact, such as flooding direction and sediment load and accumulation in the valley zone (purple colour).

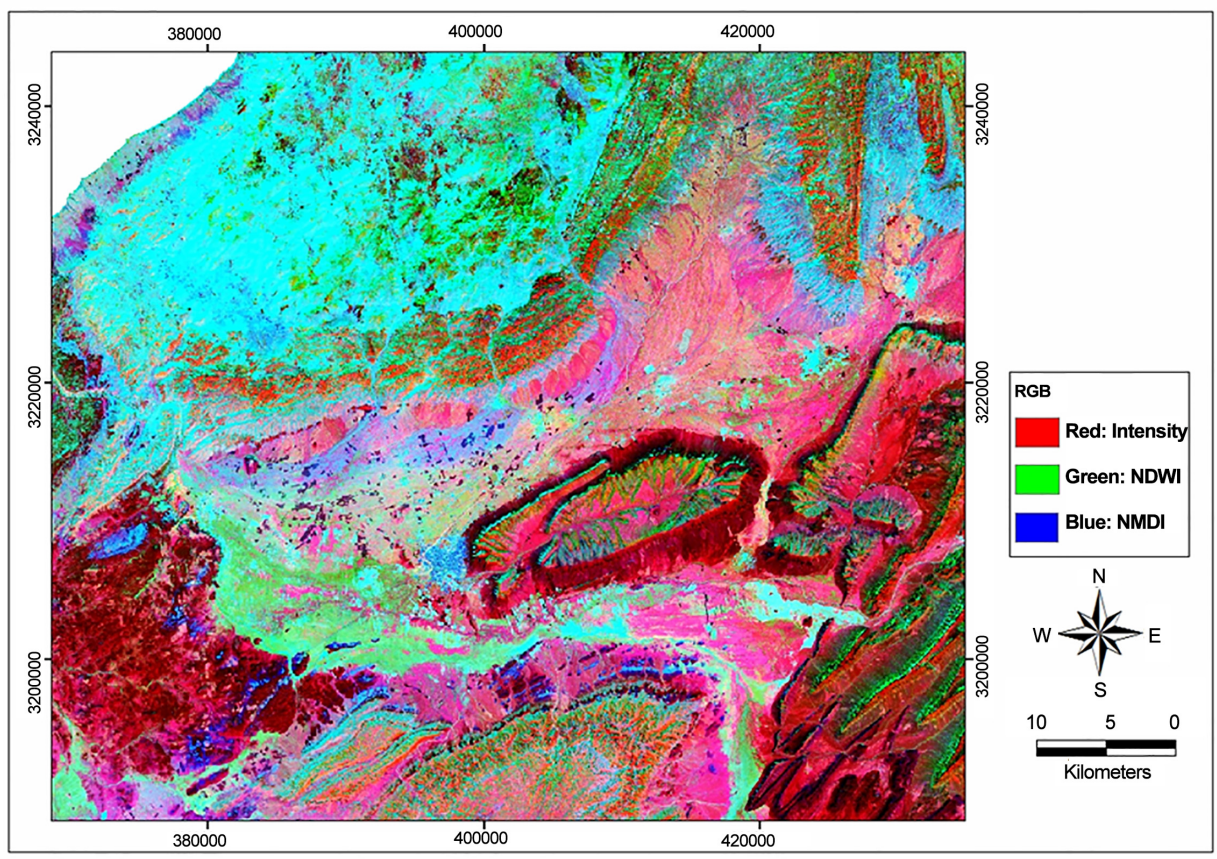

(a)

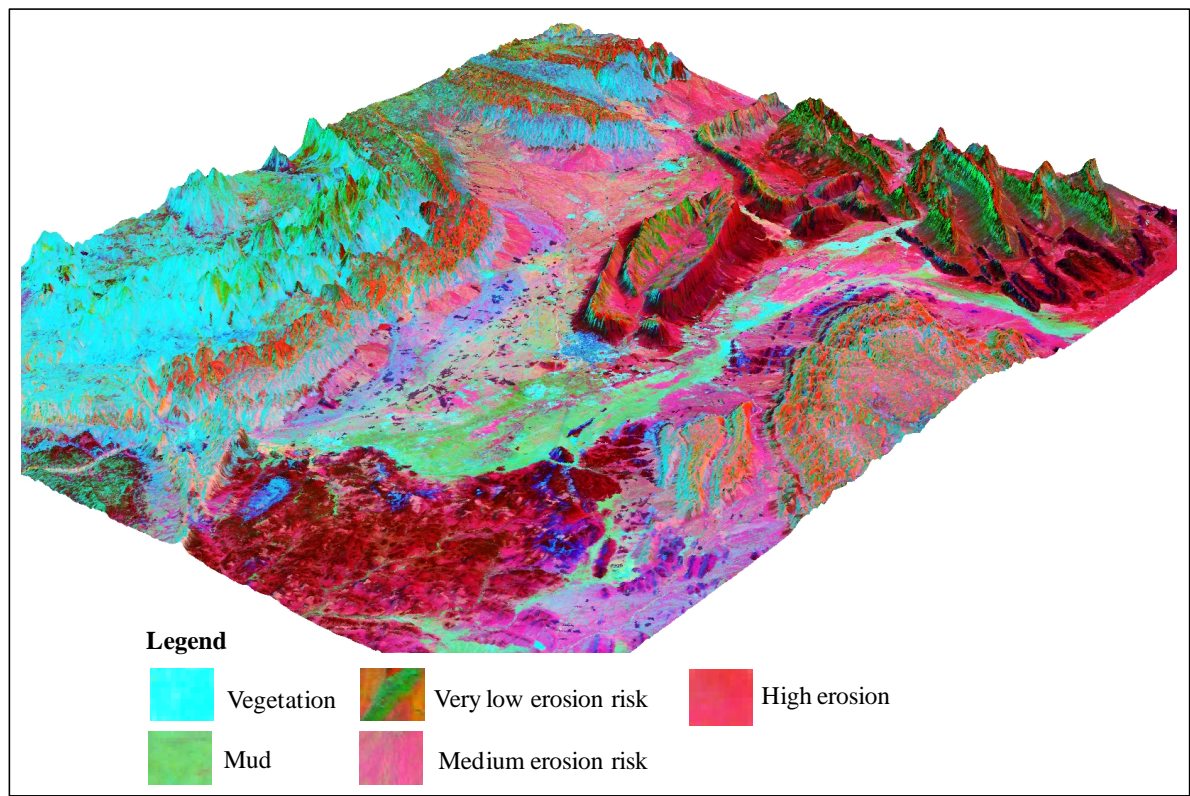

(b)

Figure 17. Map derived from the colour composite obtained by encoding intensity (I) in red, normalized difference water index (NDWI) in green, and normalized multi-band drought index (NMDI) in blue (after storm). 
Furthermore, the map based on intensity ("I"), NDWI and NMDI colour composite (Figure 17) shows identical classes and a similar discrimination capability as presented in Figure 16. The occurrence of the recent sediments, which is visible in pale green, coincides with areas assumed prone to a higher flooding susceptibility and sediment accumulation due to their geographic location. These two maps characterize the same erosion classes, especially in the valleys' broader zones and depressions surrounding high hills with steep slopes $\left(9.5^{\circ}\right.$ to $\left.26^{\circ}\right)$ and converging towards the interior of the plain. In addition, geological classes forming natural belt barriers are perfectly highlighted and mapped with the two considered combinations (Figure 16 and Figure 17), showing good correspondence with the available geological map (Figure 18). Likewise, the geological map shows the alluvial and quaternary class in yellow colour, following the slop from the mountains and hills to the direction of Guilmim city and riverbed. This class is related to soil erosion and variety of material, such as silt and clay, as well sediment deposit for centuries. The two selected combinations highlight it. According to the geology, geomorphology, pedology and topography of this area, it can be seen that the recent flash-flood storm generated similar trends of sediment transport and accumulation as illustrated with the derived maps in Figure 16 and Figure 17. This similarity constitutes clear evidence that this proposed approach is successful of detecting spatial changes in soil and vegetation conditions caused by runoff after the flood storm in the Guelmim region.

Finally, the last step of the erosion risk and sediment accumulation, caused by runoff after flood-storm analysis, is based on the integration and segmentation of the retained spectral indices (Intensity, FI, BI, NDWI and NMDI) in the two considered combinations adopting the Fuzzy-K-Means unsupervised classification. The generated thematic map characterizes the land-surface conditions as they were observed at the time of the second image acquisition (December 9), eight days after the flood-storm (Figure 19). Obviously, this approach does not provide a truthful description regarding the destruction

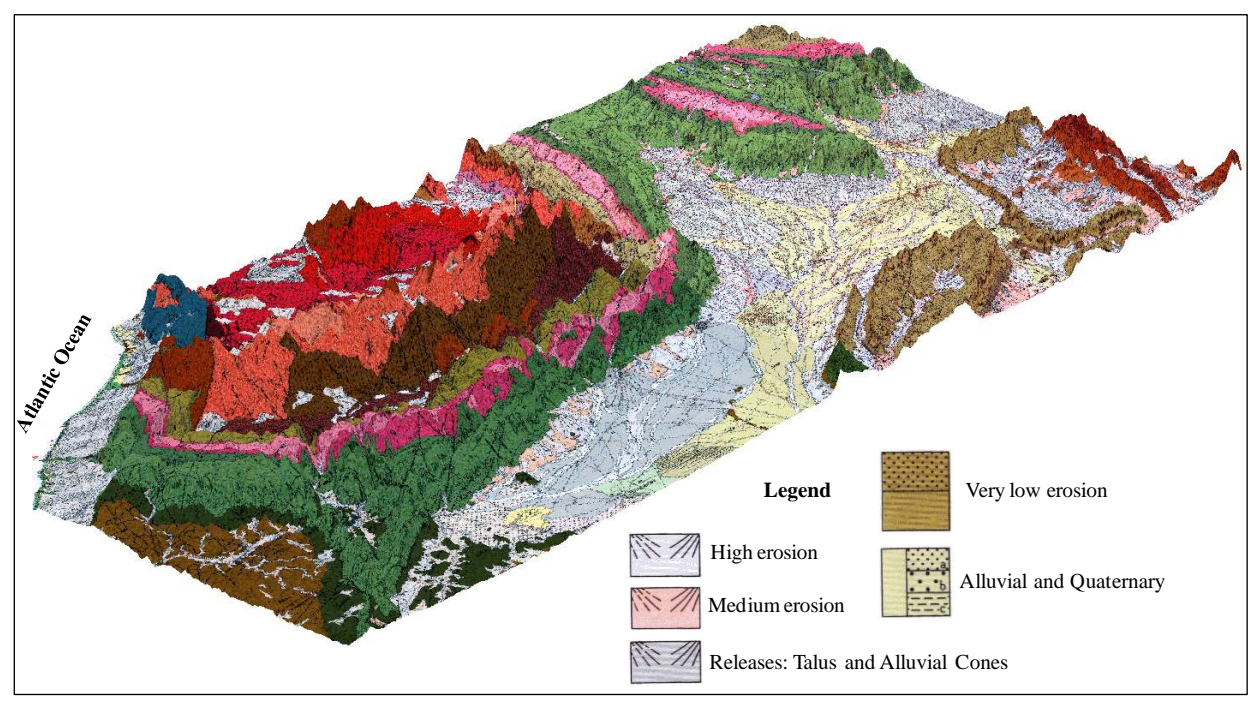

Figure 18. Geological map of a part of the study area. 

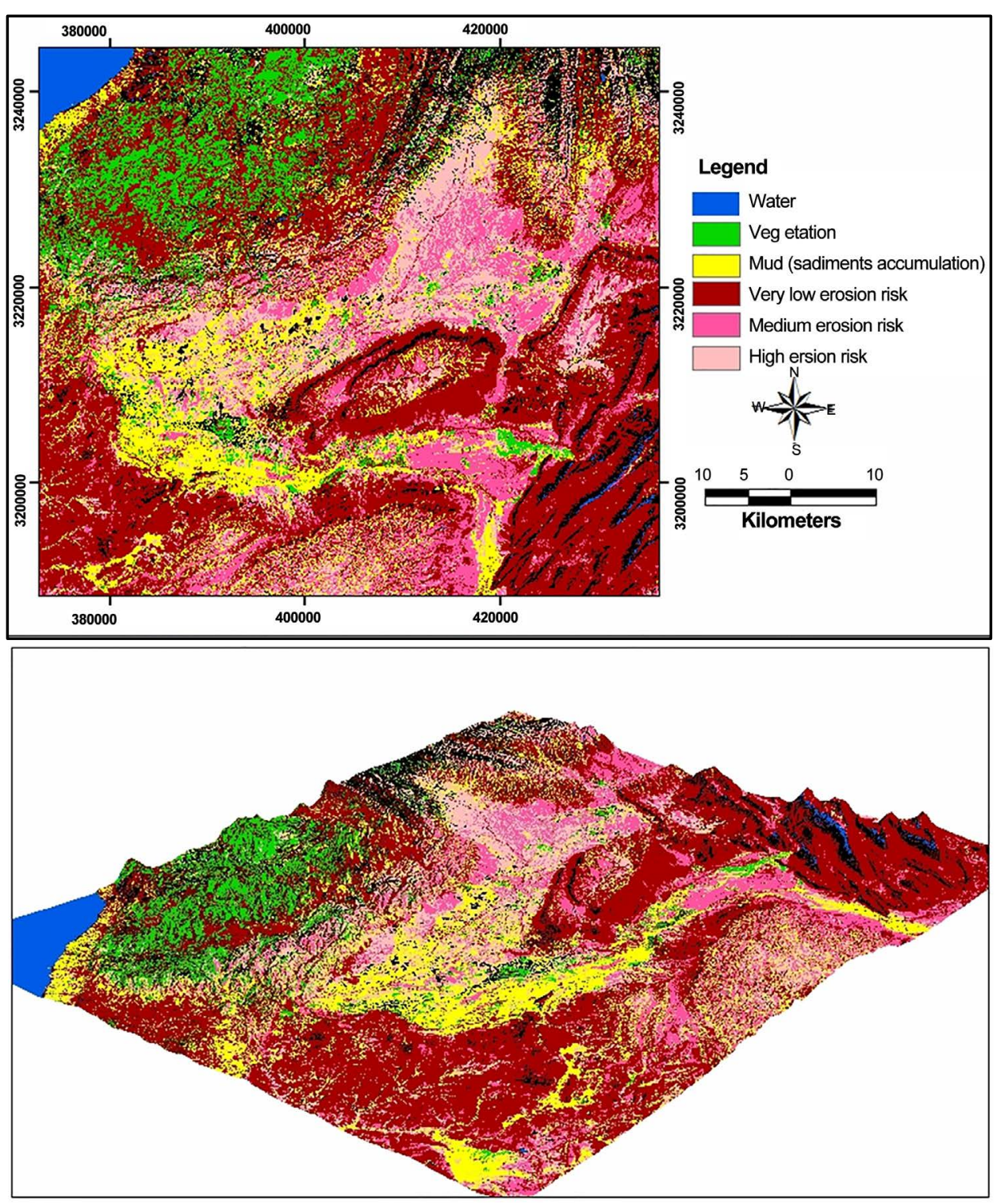

Figure 19. Derived erosion risk and sediment accumulation map (after flood).

of the Guelmim ecosystem and its future evolution. This needs to be further analyzed in the context of an ecologically based framework involving multidisciplinary approaches [13]. However, this proposed and simplified approach assesses ecosystem vulnerability to land degradation by water erosion and sediment accumulation. Spectral information is combined and grouped to analyze land classes and geo-morphological units, characterizing landscape susceptibility to hydrologic processes and defining homogeneous land units with similar response to erosion risk and degradation processes. As explained previously, relief and vegetation cover are important factors in determining runoff aggressiveness, and chemical and physical properties of substrate materials control consolidation and erodibility by water.

The Fuzzy-K-Means unsupervised classification led to 16 classes, which were re- 
grouped into six homogeneous classes. They are ordered based on their relative sensitivity to water erosion as recommended by other scientists [13] [126]. Thus, in addition to water and vegetation classes, four other classes, mud (sediment accumulation), and very low, medium, and high soil erosion risk, were considered based on the lithology, geology and topographic characteristics of the study area. The mud class is located on areas responding to hydrological processes and topographic morphology, forming a natural basin that facilitates flow accumulation and is prone to inundation and sediment accumulation. This result is in agreement with our expectation during the topographic profile analysis based on independent datasets (Figure 11). In addition, as explained in the previous section, the geological map illustrates this class as alluvial-quaternary (Figure 19). The very low erosion-risk class is located in areas characterized by high altitudes and steep slopes and highlighting the volcanic rocks of the Precambrian (rhyolite and andsite). The latter is resistant and forms the highest peaks of the mountains (boutonniere of Ifni, Jabel Bani, Jabel Taissa and Jabel Tayert). For this class, significant presence of vegetation cover is observed, especially in the NW region. The medium erosion risk class shows intermediate to low slopes in the release zones (talus and alluvial cones) with black limestone, lacustre limestone, dolomite, marl, spreading silt, and lime stonecrusts (Figure 7). Moreover, by reference to the lithological and geological maps (Figure 7 and Figure 18), the areas classified with high erosion potential risk are formed with schist (soft rocks) and limestone formations, which are characterised by a high erodibility and none to very low vegetation recovery. These zones are related to the steep slopes and ridges, ravines and water streams, which are the most important contributing factors to erosion and land-degradation process.

The derived erosion risk and sediment accumulation map (Figure 19) based on remote sensing image data and topographic attributes illustrated the tendency of water accumulation in the landscape, and highlights areas prone to both fast moving and pooling water. They described the ability to transfer sediment in a channel's stream and evaluate the flood risks in basin hydrology. They explicitly demonstrated the sediment flow convergence and divergence from the top of the mountains to the areas prone to inundation and sediment accumulation. Moreover, they demonstrated that the rainfall and the topographic morphology are the major contributing factors to flash flooding and catastrophic inundation in the study area. The runoff-water power delivers vulnerable topsoil, contributes strongly to the erosion, and transports soil materials and sediments to the plain areas through water power and gravity. Likewise, the role of the lithology associated with the terrain morphology is decisive in the erosion risk and land degradation in this region. These research results can help in the improvement of the management of water regulation structures; because there is an imperative need to develop a methodology to maximize the water storage capacity and to reduce the risks caused by floods in the Guelmim region. This study demonstrated that remote sensing science and technologies associated with GIS and auxiliary data have become the fundamental solution for flood monitoring, understanding, and its impact assessment to provide a solid basis strategy for regional policies to address the real causes of problems 
and risks. Consequently, this synergy provides ideas about how flood waters must be channeled, diverted and drained. Without doubt, information technology is not the only issue; solutions must be considered from different perspectives, such as based on social, human, and financial aspects and at different levels of public policy and decision-making. Obviously, political commitments must be sincere to apply these flood resilience measurements and strategies.

\section{Conclusions}

This research deal with the characterization of areas associated with flash floods and erosion caused by severe rainfall storm and sediment transport and accumulation using topographic profiles and spectral indices. Topographic attributes and profiles were retrieved fromASTER-V2.1 DEM using GIS technology. Whereas the remote sensing approach integrates spectral indices, such as the FI, the $\mathrm{CI}$ and the $\mathrm{BI}$, which describes the soil reflectance curve. In addition, the "I", "H" and "S" that correspond to soil colour brightness, colour spectral dominance as well as colour purity, respectively, have been also considered.PCA as indicators of soil state and land use based on de-correlation statistics between the spectral bands has also been integrated. Based on the assumption that vegetation protects soils from erosion and degradation, vegetation indices, such as the TDVI, was also used. In addition to this characterization process, soil moisture conditions and vegetation water content were integrated, exploiting the NDWI and the NMDI. All these indices were derived from two Landsat-OLI images acquired before and after the flood-storm. The OLI images data were atmospherically corrected, sensor radiometric drift calibrated, and geometric and topographic distortions rectified. For validation purposes, the acquired photos during the flood-storm, lithological and geological maps were used.

The results show that the NDWI characterizes correctly soil and vegetation moisture content before and after flooding than NMDI. TDVI describes correctly the scattered vegetation along the riverbed, on the top of mountains and in oases. The "I" and "S" parameters allowed a significant discrimination between various rock types and soil degradation levels. Nevertheless, the " $H$ " showed exceptional results for lithological formation discrimination. As well, the soil spectral indices (CI, FI and BI) demonstrated the powerful synergy to discriminate correctly among rocks and soil classes, the mud and sediment direction and accumulation zones. The analysis of approximately 100 false colour composite combinations in the RGB PCI-Geomatica system then permitted the selection of two combinations due to their potential for characterizing soil erosion classes and sediment accumulation. The first considers the "Intensity, NDWI and NMDI", while the second associates "FI, BI and NDWI". Validation of results shows that these two combinations provide very good separating power between different levels of soil erosion and degradation, particularly among different land-cover classes in a semi-arid environment.

Furthermore, based on the selected indices, the landscape segmentation into different units has been carried out generating a thematic map of land erosion risk and sedi- 
ment accumulation caused by runoff after the flood-storm. Globally, this research demonstrated that the rainfall and the topographic morphology are the major contributing factors for flash flooding and catastrophic inundation in the study area. The runoff-water power delivers vulnerable topsoil and contributes strongly to the erosion and land-degradation process, and then transports soil material and sediment to the plain areas through water power and gravity. The high levels of aggressiveness are encountered in the valleys and over areas with steeper slopes. The valleys are zones of flow accumulation, receiving the contribution of large upslope drainage areas, thus, allowing high rates of erosion. Low runoff aggressiveness is connected with areas of low slopes. Likewise, the role of the lithology associated with the terrain morphology is decisive in the erosion risk and land degradation in this region.

Undoubtedly, the originality of this research resides in its simplicity and rapidity to provide a solid basis strategy for regional policies to address the real causes of problems and risks in developing countries. Indeed, the obtained results can help in the improvement of the management of water regulation structures to develop a methodology to maximize the water storage capacity and to reduce the risks caused by floods in the Guelmim region. Moreover, they demonstrated that remote sensing science and technologies associated with GIS and auxiliary data have become the fundamental solution for flood monitoring, understanding, and its impact assessment.

\section{Acknowledgements}

The authors would like to thank the Arabian Gulf University (AGU) for their financial support. We would like to thank the NASA-GLOVIS-GATE for the OLI data and the LP-DAAC NASA-USGS for the ASTER GDEM data. Our gratitude goes to many people who have made the used photos available on the web for consultation and public use, as well for Professor Karl Staenz from University of Lightbridge (Alberta, Canada) for his critical review of this paper. Finally, we express gratitude to the anonymous reviewers for their constructive comments

\section{References}

[1] Cai, X., Zhang, X., Noël, P.H. and Shafiee-Jood, M. (2015) Impacts of Climate Change on Agricultural Water Management: A Review. WIREs Water, 2, 439-455. https:/doi.org/10.1002/wat2.1089

[2] Bannari, A., El-Harti, A., Haboudane, D., Bachaoui, M. and El-Ghmari, A. (2008) Intégration des variables spectrales et géomorphométriques dans un SIG pour la cartographie des zones exposées à l'érosion. Revue Télédétection, 7, 393-404.

[3] Maimouni, S., Bannari, A.,El-Hrati, A. and El-Ghmari, A. (2012) Potentiels et limites des indices spectraux pour caractériser la dégradation des sols en milieu semi-aride. Journal Canadien de Télédétection, 37, 285-301.

[4] Erskine, W.D. and Saynor, M.J. (1996) Effects of Catastrophic Floods on Sediment Yields in Southeastern Australia. Erosion and Sediment Yield: Global and Regional Perspectives. Proceedings of the Exeter Symposium, UK, 15-19 July, 381-388.

[5] SIGMA (2015) Natural Catastrophes and Man-Made Disasters in 2014: Convective and 
Winter Storms Generate Most Losses. Swiss Re sigma, No. 2, 50.

http://www.biztositasiszemle.hu/files/201503/sigma2_2015_en.pdf

[6] De-Nil, D. and Saidi, A.D. (2015) Morocco Floods of 2014: What We Can Learn from Guelmim and Sidi Ifni. Zurich Insurance Company Ltd. and Targa-AIDE Publication. Edited and Produced by Corporate Publishing, Zurich Insurance Group, 29 p.

[7] McDermid, G.J. and Franklin, S.E. (1994) Spectral, Spatial, and Geomorphometric Variables for Remote Sensing of Slope Processes. Remote Sensing of Environment, 49, 57-71. https:/doi.org/10.1016/0034-4257(94)90059-0

[8] Sanyal, J. and Lu, X.X. (2004) Application of Remote Sensing in Flood Management with Special Reference to Monsoon Asia: A Review. Natural Hazards, 33, 283-301.

https:/doi.org/10.1023/B:NHAZ.0000037035.65105.95

[9] Huete, A.R. (1988) A Soil Vegetation Adjusted Index (SAVI). Remote Sensing of Environment, 25, 295-309. https:/doi.org/10.1016/0034-4257(88)90106-X

[10] Bannari, A., Huete, A.R., Morin, D. and Zagolski, F. (1996) Effets de la couleur et de la brillance des sols sur les indices de végétation. International Journal of Remote Sensing, 17, 1885-1906. https:/doi.org/10.1080/01431169608948745

[11] Escadafal, R., Belghit, A. and Ben-Moussa, A. (1994) Indices spectraux pour la télédétection de la dégradation des milieux naturels en Tunisie aride. In: Guyot, G. réd., Actes du $6^{\text {eme }}$ Symposium international sur les mesures physiques et signatures en télédétection, Val d'Isère (France), 17-24 Janvier 1994, 253-259.

[12] Escadafal, R. and Bacha, S. (1996) Strategy for the Dynamic Study of Desertification. Proceedings of the ISSS International Symposium Ouagadougou, Burkino Faso, 6-10 February 1995, 19-34.

[13] Haboudane, D., Bonn, F., Royer, A., Sommer, S. and Mehl, W. (2002) Land Degradation and Erosion Risk Mapping by Fusion of Spectrally Based Information and Digital Geomorphometric Attributes. International Journal of Remote Sensing, 18, 3795-3820. https:/doi.org/10.1080/01431160110104638

[14] Smith, M.O., Adams, J.B. and Sabol, D.E. (1994) Mapping Sparse Vegetation Canopies. In: Hill, J. and Megier, J. Eds., Imaging Spectrometry: A tool for Environmental Observations, Kluwer Academic Publishers, Dordrecht, 221-235. https:/doi.org/10.1007/978-0-585-33173-7_12

[15] Baumgardner, M.F., Sylva, L.F., Biehl, L.L. and Stoner, E.R. (1985) Reflectance Properties of Soil. Advances in Agronomy, 38, 1-44. https:/doi.org/10.1016/S0065-2113(08)60672-0

[16] Hill, J., Mehl, W. and Altherr, M. (1994) Land Degradation and Soil Erosion Mapping in a Mediterranean Ecosystem. In: Hill, J. and Megier, J. Eds., Imaging Spectrometry-A Tool for Environment Observations, Kluwer Academic Publishers, Dordrecht, 237-260. https:/doi.org/10.1007/978-0-585-33173-7_13

[17] Escadafal, R. (1993) Remote Sensing of Soil Color: Principles and Applications. Remote Sensing Reviews, 7, 261-279. https:/doi.org/10.1080/02757259309532181

[18] Yésou, H., Besnus, Y. and Rolet, J. (1993) Extraction of Spectral Information from Landsat TM Data and Merger with SPOT Panchromatic Imagery-A Contribution to the Study of Geological Structures. ISPRS Journal of Photogrammetry and Remote Sensing, 48, 23-36. https:/doi.org/10.1016/0924-2716(93)90069-Y

[19] Floras, S.A. and Sgouras, I.D. (1999) Use of Geoinformation Techniques in Identifying and Mapping Areas of Erosion in a Hilly Landscape of Central Greece. International Journal of Applied Earth Observation and Geinformation, 1, 68-77. https:/doi.org/10.1016/S0303-2434(99)85030-2 
[20] Manal, A.K. (2007) Spectral Mixture Analysis for Monitoring and Mapping Desertification Processes in Semi-Arid Areas in North Kordofan State, Sudan. Doctorate Thesis in Geo and Hydro Sciences, Institute of Photogrammetry and Remote Sensing, Dresden Technic University of Forest, Germany, 54 p.

[21] Benchallal, A., Oukil, A. and Belhajd-Aissa, A. (2009) Identification et détection, par imagerie satellitaire, de la dégradation des sols par la salinité dans la cuvette de Ouargla, sud de l'Algérie. Journées d'Animation Scientifique (JAS09) de I AUF Alger, 1-6.

[22] Gao, B.C. (1996) NDWI-A Normalized Difference Water Index for Remote Sensing of Vegetation Liquid Water from Space. Remote Sensing of Environment, 58, 257-266. https:/doi.org/10.1016/S0034-4257(96)00067-3

[23] Wang, L. and Qu, J.J. (2007) NMDI: A Normalized Multi-Band Drought Index for Monitoring Soil and Vegetation Moisture with Satellite Remote Sensing. Geophysical Research Letters, 34, 1-5. https:/doi.org/10.1029/2007GL031021

[24] Jain, S.K., Singh, R.D., Jain, M.K. and Lohani, A.K. (2005) Delineation of Flood-Prone Areas Using Remote Sensing Techniques. Water Resources Management, 19, 333-347. https:/doi.org/10.1007/s11269-005-3281-5

[25] Ji, L., Zhang, L. and Wylie, B. (2009) Analysis of Dynamic Thresholds for the Normalized Difference Water Index. Photogrammetric Engineering and Remote Sensing, 75, 1307 1317. https:/doi.org/10.14358/PERS.75.11.1307

[26] Bangira, T. (2013) Mapping of Flash Flood Potential Areas in the Western Cap (South Africa) Using Remote Sensing and in Situ Data. Master Thesis, Faculty of Geo-Information Science and Earth Observation, University of Twente, South Africa, 57 p.

[27] Chen, C.F., Valdez, M.C., Chang, N.B., Chang, L.Y. and Yuan, P.Y. (2014) Monitoring Spatiotemporal Surface Soil Moisture Variations During Dry Seasons in Central America With Multisensor Cascade Data Fusion. IEEE Journal of Selected Topics in Applied Earth Observations and Remote Sensing, 7, 4340-4355. https:/doi.org/10.1109/JSTARS.2014.2347313

[28] Bannari. A., Haboudane, D. and Bonn, F. (2000) Intérêt du moyen infrarouge pour la cartographie des résidus de cultures. Journal Canadien de Télédétection, 26, 384-393. https:/doi.org/10.1080/07038992.2000.10855270

[29] Bannari, A., Pacheco, A., Staenz, K., McNairn, H. and Omari, K. (2006) Estimating and Mapping Crop Residue Cover in Agricultural Lands Using Hyperspectral and IKONOS data. Remote Sensing of Environment, 104, 447-459. https:/doi.org/10.1016/j.rse.2006.05.018

[30] Dijon, R. and El Hebil A. (1977) Bassin de l'oued Noun et basins côtiers d'Ifni au Draa. In: Ressources en eaux du Maroc. Notes et Mémoires du Service Géologique du Maroc, № 231, Tome 3, 438 pages.

[31] Weisrock, A., Wengler, L., Mathieu, J., Ouammou, A., Fontugne, M., Mercier, N., Reyss, J.L., Valladas, H. and Guery, P. (2006) Upper Pleistocene Comparative OSL, U/Th and 14C Datings of Sedimentary Sequences and Correlative Morphodynamical Implications in the South-Western Anti-Atlas (Oued Noun, $29^{\circ}$ N, Morocco). Quaternaire, 17, 45-59. https:/doi.org/10.4000/quaternaire.645

[32] Wengler, L., Weisrock, A., Brochier, J.E., Brugal, J.-P., Fontugne, M., Magnin, F., Mathieu, J., Mercier, N., Ouammou, A., Reyss, J.-L., Senegas, F., Valladas, H. and Wahl, L. (2002) Enregistrement fluviatile et paléo-environnements au Pléistocène supérieur sur la bordure méridionale atlantique de l'Anti-Atlas (Oued Assaka, S-O marocain). Quaternaire, 13, 179192. https:/doi.org/10.3406/quate.2002.1710

[33] Choubert, G. (1963) Histoire géologique du Précambrian de l'Anti-Atlas. Tome 1. Notes et Mémoires, Service Géologique du Maroc, №162, 352 p. 
[34] Naser, N. (2006) Utilisation des Systeme d'Information Géographiques en Hydrogéologie en Vue de l'éboration d'un Outil de Gestion des Ressources en Eau du Bassin de Guelmim. Institut Agronomique et Veterinaire (IAV), Hassan II, Rabat, Royaume du Maroc, Memoire de Troixieme Cycle Pour l'obtention du Diplôme d’Ingénieur d'Etat en Génie Rural. http://www.spate-irrigation.org/wordpress/wp-content/uploads/2011/06/MemoireNaserNaj lae_GR_2006.pdf

[35] NASA (2014) METI and NASA Release the ASTER Global DEM. https://lpdaac.usgs.gov/about/news_archive/meti_and_nasa_release_aster_global_dem

[36] NASA (2011) ASTER Global Digital Elevation Map Announcement. https://asterweb.jpl.nasa.gov/gdem.asp

[37] Chrysoulakis, N., Abrams, M., Feidas, H. and Velianitis, D. (2004) Analysis of ASTER Multispectral Stereo Imagery to Produce Dem and Land Cover Databases for Greek Islands: The Realdems Project. In: Prastacos, P., Cortes, U., de Leon, J.L. and Murillo, M., Eds., Proceedings of Environment: Progress and Challenges, Instituto Politecnico Nacional, Mexico, 411-424.

[38] Toutin, T. (2002) Impact of Terrain Slope and Aspect on Radargrammetric DEM Accuracy. ISPRS Journal of Photogrammetry and Remote Sensing, 57, 228-240. https:/doi.org/10.1016/S0924-2716(02)00123-5

[39] Hirt, C., Filmer, M. and Featherstone, W.E. (2010) Comparison and Validation of the Recent Freely Available ASTER-GDEM ver1, SRTM ver4. 1 and GEODATA DEM-9S ver3 Digital Elevation Models over Australia. Australian Journal of Earth Sciences, 57, 337-347. https:/doi.org/10.1080/08120091003677553

[40] ERSDAC (2011) ASTER-GDEM Version 2, Validation Report, Japons Validation Report, $24 \mathrm{p}$. http://www.jspacesystems.or.jp/ersdac/GDEM/ver2Validation/Appendix_A_ERSDAC_GD EM2_validation_report.pdf

[41] Meyer, D. (2011) ASTER GDEM Version 2-Summary of Validation Results. 27 p. https://lpdaacaster.cr.usgs.gov/GDEM/Summary_GDEM2_validation_report_final.pdf

[42] USGS (2015) Global Data Explorer for ASTER GDEM Accessibility. http://gdex.cr.usgs.gov/gdex/

[43] Bannari, A. and Kadhem, G. (2016) Comparison of SRTM-V4.1 and ASTER-V2.1 for Accurate Hydrologic Variable Extraction in Flooded Areas. Remote Sensing, 25 p (Submitted).

[44] NASA (2015) Operational Land Imager (OLI). http://landsat.gsfc.nasa.gov/?p=5447

[45] Bannari, A., Teillet, P.M. and R. Landry (2004) Comparaison des réflectances des surfaces naturelles dans les bandes spectrales homologues des capteurs TM de Landsat-5 et TME+ de Landsat-7. Revue Télédétection, 4, 263-275.

[46] Wulder, M.A., White, J.C., Masek, J.G., Dwyer, J. and Roy, D.P. (2012) Continuity of Landsat Observations: Short Term Considerations. Remote Sensing of Environment, 115, 747-751. https:/doi.org/10.1016/j.rse.2010.11.002

[47] NASA (2014) Landsat-8 Instruments. http://www.nasa.gov/mission_pages/landsat/spacecraft/index.html

[48] Markham, D., Goward, S., Arvidson, T., Barsi, J. and Scaramuzza, P. (2006) Landsat-7 Long-Term Acquisition Plan Radiometry-Evolution over Time. Photogrammetric Engineering and Remote Sensing, 72, 1129-1135. https:/doi.org/10.14358/PERS.72.10.1129

[49] Knight, E.J. and Kvaran, G. (2014) Landsat-8 Operational Land Imager Design, Characterization and Performance. Remote Sensing, 6, 10286-10305. 
https:/doi.org/10.3390/rs61110286

[50] Markham, B.L., Dabney, P.W., Storey, J.C., Morfitt, R., Knight, E.G., Kvaran, G. and Lee, K. (2008) Landsat Data Continuity Mission Calibration and Validation. Proceedings of the PECORA 17 Conference, Denver, Colorado, USA, 18-20 November 2008, 7 p.

[51] Markham, B., Barsi, J., Kvaran, G., Ong, L., Kaita, E., Biggar, S., Czapla-Myers, J., Mishra, N. and Helder, D. (2014) Landsat-8 Operational Land Imager Radiometric Calibration and Stability. Remote Sensing, 6, 12275-12308. https:/doi.org/10.3390/rs61212275

[52] Morfitt, R., Barsi, J., Levy, R., Markham, B., Micijevic, E., Ong, L., Scaramuzza, P. and Vanderwerff, K. (2015) Landsat-8 Operational Land Imager (OLI) Radiometric Performance On-Orbit. Remote Sensing, 7, 2208-2237. https:/doi.org/10.3390/rs70202208

[53] Myneni, R.B. and Asrar, G. (1994) Atmospheric Effects and Spectral Vegetation Indices. Remote Sensing of Environment, 17, 390-402. https:/doi.org/10.1016/0034-4257(94)90106-6

[54] Bannari, A., Teillet, P.M. and Richardson, G. (1999) Nécessité de l'étalonnage radiométrique et standardisation des données de télédétection. Journal Canadien de Télédétection, 25, 4559.

[55] Pahlevan, N., Lee, Z., Wei, J., Schaaf, C.B., Schott, J.R. and Berk, A. (2014) On-Orbit Radiometric Characterization of OLI (Landsat-8) for Applications in Aquatic Remote Sensing. Remote Sensing of Environment, 154, 272-284. https:/doi.org/10.1016/j.rse.2014.08.001

[56] Vanhellemont, Q. and Ruddick, K. (2014) Turbid Wakes Associated with Offshore Wind Turbines Observed with Landsat 8. Remote Sensing of Environment, 145, 105-115. https:/doi.org/10.1016/j.rse.2014.01.009

[57] Vermote, E.F., Tanré, D., Deuze, J.L., Herman, M. and Morcrette, J.J. (1997) Second Simulation of the Satellite Signal in the Solar Spectrum, 6S: An Overview. IEEE Transactions on Geoscience and Remote Sensing, 35, 675-686. https:/doi.org/10.1109/36.581987

[58] Tanré, D. (1982) Interaction rayonnement-aérosols: Applications à la télédétection et au calcul du bilan radiatif. Thèse de doctorat d'État, Université des sciences et techniques de Lille, Lille (France), 258 p.

[59] Teillet, P.M. and Santer, R.P. (1991) Terrain Elevation and Sensor Altitude Dependence in Semi-Analytical Atmospheric Code. Canadian Journal of Remote Sensing, 17, 36-44.

[60] Richards, J.A. (1993) Remote Sensing Digital Image Analysis: An Introduction. SpringerVerlag, Berlin, 340 p. https:/doi.org/10.1007/978-3-642-88087-2

[61] Teillet, P.M. (1992) An Algorithm for the Radiometric and Atmospheric Correction of AVHRR Data in the Solar Reflective Channels. Remote Sensing of Environment, 41, 185195. https:/doi.org/10.1016/0034-4257(92)90077-W

[62] Storey, J., Choate, M. and Lee, K. (2014) Landsat-8 Operational Land Imager On-Orbit Geometric Calibration and Performance. Remote Sensing, 6, 11127-11152. https:/doi.org/10.3390/rs61111127

[63] Bannari, A., Morin, D., Bénié, G.B. and Bonn, J.F. (1995) A Theoretical Review of Different Mathematical Models of Geometric Corrections Applied to Remote Sensing Images. Remote Sensing Reviews, 13, 27-47. https:/doi.org/10.1080/02757259509532295

[64] Caloz, R. and Collet, C. (2001) Précis de Télédétection. Volume III : Traitements Numériques d’Images de Télédétection. Presses Universitaires du Québec-Agence Universitaire de la Francophonie, $386 \mathrm{p}$.

[65] Caloz, R., Blaser, T.J. and Willemin, G. (1993) Création d'ortho-image à l'aide d'un modèle numérique d'altitude-Influences des modes de rééchantillonnage radiométrique. In Dubois, J.-M.M., Cavayas, F. et Lafrance, P., réd., Télédétection appliquée à la cartographie thématique 
et topographique. Actes des $4^{\text {eme }}$ journées scientifiques du Réseau Télédétection de 1 AUPELFUREF, Montréal, 21-23 Octobre 1991, Presses de l'Université du Québec et AUPELF, SainteFoy et Montréal, 17-30.

[66] Burrough, P.A. and McDonnell, R.A. (2000) Principles of Geographical Information Systems; Spatial Information Systems and Geostatistics. Oxford University Press, Oxford, 333 p.

[67] PCI Geomatics (2015) Using PCI Software. Richmond Hill, Ontario, Canada, 540 p.

[68] Radeloff, V., Hill, J. and Mehl, W. (1997) Forest Mapping from Space: Enhanced Satellite Data Processing by Spectral Mixture Analysis and Topographic Corrections. Space Applications Institute, Environmental Mapping and Modeling Unit, European Commission, Ispra (Italie), $88 \mathrm{p}$.

[69] Irons, J.R., Weismiller, R.A. and Petersen, G.W. (1989) Soil Reflectance. In: Asrar, G., Ed., Theory and Applications of Optical Remote Sensing, John Wiley \& Sons, Inc., New York, 66-106.

[70] Girard, M.C. and C.M. Girard (1989) Télédétection appliquée: Zones tempérées et intertropicales. Éditions Masson, Paris, 260 p.

[71] Legros, J.P. (1996) Cartographies des sols : De l'analyse spatiale à la gestion des territoires. Collection Gérer l'environnement. Presses Polytechniques et Universitaires Romandes, Lausanne, Suisse, $321 \mathrm{p}$.

[72] Belghith, A. (2003) Les indicateurs radiométriques pour l'étude de la dynamique des écosystèmes arides (région de Zougrarta, Sud-Est tunisien). Revue Sécheresse, 14, 267-274.

[73] Haboudane, D. (1999) Intégration des données spectrales et géomorphométriques pour la caractérisation de la dégradation des sols et l'identification des zones de susceptibilité à l'érosion hydrique. Thèse de doctorat (Ph.D), Département de Géographie et Télédétection, Université de Sherbrooke, Sherbrooke, Québec, Canada, 174 p.

[74] Escadafal, R., Girard, M.C. and Courault, D. (1989) Munsell Soil Color and Reflectance in the Visible Spectral Bands of Landsat MSS and MT Data. Remote Sensing of Environment, 27, 37-46. https:/doi.org/10.1016/0034-4257(89)90035-7

[75] Escadafal, R. and Huete, A.R. (1991) Étude des propriétés spectrales des sols arides appliquée à l'amélioration des indices de végétation obtenus par télédétection. Comptesrendus de 1 Académie des Sciences de Paris, Paris, France, Série 312, 1385-1391.

[76] Post, D.F., Horvath, E.H., Lucas, W.M., White, S.A., Ehasz, M.J. and Batchily, A.K. (1994) Relation between Soil Color and Landsat Reflectance on Semiarid Rangelands. Soil Science Society of America Journal, 58, 1809-1816. https:/doi.org/10.2136/sssaj1994.03615995005800060033x

[77] Mougenot, B. and Cailleu, D. (1995) Identification par télédétection des sols dégradés d'un domaine sahélien au Niger. Actes du Symposium International AISS (groupe de travail RS et DM), Ouagadougou, Burkina Faso, 6-10 février 1995, 169-179.

[78] Chikhaoui, M., Bonn, F. Merzouk, A., Lacaze, B. and Mejjati, A.M. (2007) Cartographie de la dégrdation des sols à l'aide des approches de Spectral Angle Mapper et des indices spectraux en utilisant des données ASTER. Revue Télédétection, 7, 343-357.

[79] Escadafal, R. (1989) Caractérisation de la surface des sols arides par observations de terrain et par télédétection. Thèse de Doctorat d'État en pédologie, Université de Paris VI, Paris, Frances, $317 \mathrm{p}$.

[80] Mathieu, R. and Pouget, M. (1998) Relationships between Satellite-Based Radiometric Indices Simulated using Laboratory Reflectance Data and Typic Soil Colour of an Arid Environment. Remote Sensing of Environment, 66, 17-28. 
https:/doi.org/10.1016/S0034-4257(98)00030-3

[81] Ghram-Messedi, A. and Delaître, E. (2007) Les états de surface en zone aride à partir d'indices radiométriqueset de classifications multitemporelles d'images Landsat TM prises sur la région de Menzel Habib (Tunisie méridionale). Revue Sécheresse, 18, 305-313.

[82] Levin, N., Ben-Dor, E. and Singer, A. (2005) A Digital Camera as a Tool to Measure Color Indices and Related Properties of Sandy Soils in Semi-Arid Environments. International Journal of Remote Sensing, 26, 5475-5492. https:/doi.org/10.1080/01431160500099444

[83] Levin, N., Tsoar, H., Maia, L. P., Claudino-Sales, V. and Herrmann, H. (2007) Dune Whitening and Inter-Dune Freshwater Fonds in NE Brazil. Catena, 70, 1-15. https:/doi.org/10.1016/j.catena.2006.06.006

[84] Mougenot, B. (1990) Caractéristiques spectrales des surfaces salées à chlorures et sulfates

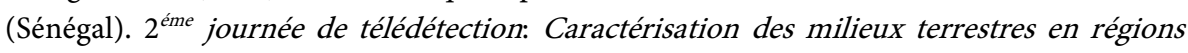
arides et tropicales. Colloques et séminaires. ORSTOM, Bondy, 49-70.

[85] Ouerchefani, D., Taamallah, H. and Belghith, A. (2008) Apport de la classification spectrale des compositions colorées des indices pour la cartographie des sols salins dans un milieu aride du Sud tunisien. Journal Canadien de Télédétection, 34, 438-446. https:/doi.org/10.5589/m08-063

[86] Escadafal, R., Gouinaud, C., Mathieu, R. and Pouget, M. (1993) Le spectroradiomètre de terrain : un outil de la télédétection et de la pédologie. Cahier-ORSTOM, Pédologie, 15-29.

[87] Liu, L.G. and Moore, J.M. (1990) Hue Image RGB Colour Composition. A Simple Technique to Suppress Shadow and Enhance Spectral Signature. International Journal of Remote Sensing, 11, 1521-1530. https:/doi.org/10.1080/01431169008955110

[88] Mattikalli, N.M. (1997) Soil Colour Modelling for the Visible and Near Infrared Bands of Landsat Sensors using Laboratory Spectral Measurements. Remote Sensing of Environment, 59, 14-28. https:/doi.org/10.1016/S0034-4257(96)00075-2

[89] Madeira, J., Bédidi, A. Cervelle, B., Pouget, M. and Flay, N. (1997) Visible Spectrometric Indices of Hematite ( $\mathrm{Hm})$ and Goethite $(\mathrm{Gt})$ Content in Lateritic Soils: the Application of a Thematic Mapper Image for Soil-Mapping in Brasilia, Brazil. International Journal of Remote Sensing, 18, 2835-2852. https:/doi.org/10.1080/014311697217369

[90] Fontes, M.P.F. and Carvalho, I.A.J. (2005) Color Attributes and Mineralogical Characteristics, Evaluated by Radiometry, of Highly Weathered Tropical Soils. Soil Science Society of America Journal, 69, 1162-1172. https:/doi.org/10.2136/sssaj2003.0312

[91] Lunden, B., Wester, K. and Bax, G. (1991) Satellite Image Enhancement for Rock Type Separation. IGARSS 91 International Geoscience and Remote Sensing Symposium, Helsinki University of Technology, Espo, Finland, 3-6 June 1991, 2047-2050.

[92] Pohl, C. and Van Genderen, J.L. (1998) Multisensor Image Fusion in Remote Sensing: Concepts, Methods and Applications (Review Article). International Journal of Remote Sensing, 19, 823-854. https:/doi.org/10.1080/014311698215748

[93] Bannari, A., El-Battay, A., Saquaque, A. and Miri, A. (2016) PALSAR-FBS L-HH Mode and Landsat-TM Data Fusion for Geological Mapping. Advances in Remote Sensing, 5, 246-268.

[94] Dwivedi, R.S., Ravi Sankar, T., Venkataratnam, L., Karale, R.L., Gawande, S.P., Seshagiri Rao, K.V., Senchaudhary, S., Bhaumik, K.R. and Mukharjee, K.K. (1997) The Inventory and Monitoring of Eroded Lands Using Remote Sensing Data. International Journal of Remote Sensing, 18, 107-119. https:/doi.org/10.1080/014311697219303

[95] Schetselar, E.M. (2001) On Preserving Spectral Balance in Image Fusion and its Advantages for Geological Image Interpretation. Photogrammetric Engineering and Remote Sensing, 67(8), 925-934. 
[96] Koutsias, N., Karteris, M. and Chuvieco, E. (2000) The Use of Intensity-Hue-Saturation Transformation of Landsat-5 Thematic Mapper Data for Burned Land Mapping. Photogrammetric Engineering and Remote Sensing, 66, 829-839.

[97] Maksud-Kamal, A.S.M. and Midorikawa, S. (2004) GIS-Based Geomorphological Mapping using Remote Sensing Data and Supplementary Geoinformation: A Case Study of the Dhaka City Area, Bangladesh. International Journal of Applied Earth Observation and Geoinformation, 6, 111-125. https:/doi.org/10.1016/j.jag.2004.08.003

[98] King, C., Baghdadi, N., Lecomte, V. and Cerdan, O. (2005) The Application of RemoteSensing Data to Monitoring and Modelling of Soil Erosion. Catena, 62, 79-93. https:/doi.org/10.1016/j.catena.2005.05.007

[99] Al-Rawashdeh, S., Saleh B. and Hamzah, M. (2006) The Use of Remote Sensing Technology in Geological Investigation and Mineral Detection in El Azraq-Jordan. Cybergeo: European Journal of Geography, Systèmes, Modélisation, Géostatistiques, 358, 1-21.

[100] Laliberte, A.S., Rango, A., Herrick, J.E., Fredrickson, E.L. and Burkett, L. (2007) An Object-Based Image Analysis Approach for Determining Fractional Cover of Senescent and Green Vegetation with Digital Plot Photography. Journal of Arid Environments, 69, 1-14. https:/doi.org/10.1016/j.jaridenv.2006.08.016

[101] Foley, J.D., Van-Dam, A., Feiner, S.K. and Hughes, J.F. (1990) Computer Graphics: Principles and Practice. 2nd Edition, Addison-Wesley Publishing Company, Boston, MA, USA, $592 \mathrm{p}$

[102] Chen, C.M., Hepner G.F. and Forster, R.R. (2003) Fusion of Hyperspectral and Radar Data using the IHS Transformation to Enhance Urban Surface Features. ISPRS Journal of Photogrammetry and Remote Sensing, 58, 19-30. https:/doi.org/10.1016/S0924-2716(03)00014-5

[103] Kruse, F.A. and Raines, G.L. (1984) A Technique For Enhancing Digital Colour Images by Contrast Stretching in Munsell Colour Space. Proceedings of the International Symposium on Remote Sensing of Environment-Remote Sensing for Exploration Geology, Colorado Springs, Colorado, USA, 16 April 1984, 755-773.

[104] Schowengerdt, R. (1997) Remote Sensing, Models and Methods for Image Processing. 2nd Edition, Academic Press, Toronto, Canada, 522 p.

[105] Richards, J.A. (1999) Remote Sensing Digital Image Analysis: An Introduction, SpringerVerlag, Berlin, Germany, 240 p. https:/doi.org/10.1007/978-3-662-03978-6

[106] Jensen, J.R. (1986) Introductory Digital Image Processing: A Remote Sensing Perspective. Prentice-Hall, Englewood Cliffs, New Jersey, USA, 379 p.

[107] Rajaonarison, M.A., Rajaonarison Raharison, L.J. and Kassim, I.A. (2004) Apport de la télédétection pour l'évaluation des risques d érosion hydrique des sols dans le bassin versant de la rivière de menaloha (région est du lac Alaotra, Madagascar). In: Bannari, A. et Blasco, F., Eds., Géorisques et télédétection. Actes des $X^{\text {emes }}$ Journées scientifiques du Réseau de Télédétection de P Agence Universitaire de la Francophonie, Ottawa, Canada, 24-29 Mai, $263 \mathrm{p}$.

[108] Soe, M., Won-In, K., Takashima, I. and Charusiri, P. (2008) Lateritic Soil Mapping of the Phrae Basin, Northern Thailand using Satellite Data. Science Asia, 34, 306-316. https:/doi.org/10.2306/scienceasia1513-1874.2008.34.307

[109] Velmurugan, A. and Guillen, G.C. (2009) Soil Resource Assessment and Mapping Using Remote Sensing and GIS. Journal Indian Society of Remote Sensing, 37, 511-525. https:/doi.org/10.1007/s12524-009-0045-3

[110] Dhakal, A.S., Amada, T., Aniya, M. and Sharma, R.R. (2002) Detection of Areas Associated 
with Flood and Erosion Caused by a Heavy Rainfall Using Multitemporal Landsat TM Data. Photogrammetric Engineering and Remote Sensing, 68, 233-239.

[111] Bannari, A., Huete, A.R., Morin, D. and Bonn, F. (1995) A Review of Vegetation Indices. Remote Sensing Reviews, 13, 95-120. https:/doi.org/10.1080/02757259509532298

[112] Rondeaux, G., Steven, M. and Tscharntke, T. (1996) Optimization of Soil-Adjusted Vegetation Indices. Remote Sensing of Environment, 55, 95-107. https:/doi.org/10.1016/0034-4257(95)00186-7

[113] Rouse, J.W., Haas, R.W., Schll, J.A, Deering, D.W. and Harlan, J.C. (1974) Monitoring the Vernal Advancement and Retrograde Adaption (Green Wav Effect) of Natural Vegetation. Greenbelt, Maryland, USA, 164 p.

[114] Huete, A.R., Liu, H.Q., Batchily, K. and Van-Leeuwen, W. (1997) A Comparison of Vegetation Indices over a Global Set of TM Images for EOS-MODIS. Remote Sensing of Environment, 59, 440-45 1 .

[115] Bannari, A., Asalhi, H. and Teillet, P.M. (2002) Transformed Difference Vegetation Index (TDVI) for Vegetation Cover Mapping. International Geoscience and Remote Sensing Symposium, Toronto, Ontario, Canada, 24-28 June 2002, 3053-3055. https:/doi.org/10.1109/IGARSS.2002.1026867

[116] Bannari, A., Ozbakir, B.A. and Langlois, A. (2007) Spatial Distribution Mapping of Vegetation Cover in Urban Environment Using TDVI for Quality of Life Monitoring. International Geosciences and Remote Sensing Symposium (IGARSS-2007), Barcelona, Spain, 2328 July 2007, 679-682.

[117] Lobell, D. and Asner, G. (2002) Moisture Effects on Soil Reflectance. Soil Sciences American Journal, 66, 722-727. https:/doi.org/10.2136/sssaj2002.7220

[118] Jensen, J.R. (2007) Remote Sensing of the Environment: An Earth Resource Perspective. In: Clarke, K.C., Ed., Prentice-Hall Series in Geographic Information Science, 2nd Edition, Prentice-Hall, Canada, Inc., Toronto, Canada, 592 p.

[119] Liu, W., Baret, F., Gu, X.F., Tong, Q., Zheng, L. and Zhang, B. (2002) Relating Soil Surface Moisture to Reflectance. Remote Sensing of Environment, 81, 238-246. https:/doi.org/10.1016/S0034-4257(01)00347-9

[120] Fabre, S., Lesaignoux, A. and Briottet, X. (2014) Estimation of Soil Moisture Content on Spectral Reflectance of Bare Soils in the 0.4 - $2.5 \mu \mathrm{m}$ Domain. Sensors, 14, 1-18.

[121] Xiao, X., Boles, S., Frolking, S., Salas, W., Moore, B., Li, C., He, L. and Zhao, R. (2002) Observation of Flooding and Rice Transplanting of Paddy Rice Fields at the Site to Landscape Scales in China Using VEGETATION Sensor Data. International Journal of Remote Sensing, 23, 3009-3022. https:/doi.org/10.1080/01431160110107734

[122] Marchi, L., Borga, M., Preciso, E. and Gaume, E. (2010) Characterization of Selected Extreme Flash Floods in Europe and Implications for Flood Risk Management. Journal of Hydrology, 394, 118-133. https:/doi.org/10.1016/j.jhydrol.2010.07.017

[123] Sairi, H., Fadil, A., Rhinane, H. and Hilali, A. (2015) Using Remote Sensing for Soil Moisture Monitoring During the Extreme Events of 2014 in Morocco. The $4^{\text {th }}$ International Geosciences and Geomatics Conference, Arabian Gulf University, Manama, Kingdom of Bahrain, 23-25 November 2015, 7 p.

[124] Bannari, A., Ghadeer, A., El-Battay, A., Hameed, N.A. and Rouai, A. (2016) Detection of Areas Associated with Flash Floods and Erosion Caused by Rainfall Storm Using Topographic Attributes, Hydrologic Indices and GIS. In: Pirasteh, S. and Li, J., Eds., Geo-Information Technologies and Earth Observation Systems for Global Changes and Natural Disaster Management, Springer, Germany. 
[125] Kruse, F.A., Lefkoff, A.B., Boardman, J.W., Heidebrecht, K.B., Shapiro, P.J. and Goetz, A.F.H. (1993) The Spectral Image Processing System (SIPS)-Interactive Visualization and Analysis of Imaging Spectrometer Data. Remote Sensing of Environment, 44, 145-163. https:/doi.org/10.1016/0034-4257(93)90013-N

[126] Melia, J. (1995) Guadalentin Basin: Remote Sensing. In: Final Report, MEDALUS Project Covering the Period of January 1991-December 1995, MEDALUS Office, London, 273-291.

Submit or recommend next manuscript to SCIRP and we will provide best service for you:

Accepting pre-submission inquiries through Email, Facebook, LinkedIn, Twitter, etc. A wide selection of journals (inclusive of 9 subjects, more than 200 journals)

Providing 24-hour high-quality service

User-friendly online submission system

Fair and swift peer-review system

Efficient typesetting and proofreading procedure

Display of the result of downloads and visits, as well as the number of cited articles Maximum dissemination of your research work

Submit your manuscript at: http://papersubmission.scirp.org/

Or contact ars@scirp.org 